\title{
Evaluation of the Community Multiscale Air Quality (CMAQ) model v5.0 against size-resolved measurements of inorganic particle composition across sites in North America
}

\author{
C. G. Nolte ${ }^{1}$, K. W. Appel ${ }^{1}$, J. T. Kelly ${ }^{2}$, P. V. Bhave ${ }^{3}$, K. M. Fahey ${ }^{1}$, J. L. Collett Jr. ${ }^{4}$, L. Zhang ${ }^{5}$, and J. O. Young ${ }^{1}$ \\ ${ }^{1}$ Atmospheric Modeling and Analysis Division, National Exposure Research Laboratory, Office of Research and \\ Development, US Environmental Protection Agency, Research Triangle Park, NC, USA \\ ${ }^{2}$ Air Quality Assessment Division, Office of Air Quality Planning and Standards, US Environmental Protection Agency, \\ Research Triangle Park, NC, USA \\ ${ }^{3}$ International Centre for Integrated Mountain Development, Kathmandu, Khumaltar, Lalitpur, Nepal \\ ${ }^{4}$ Department of Atmospheric Science, Colorado State University, Fort Collins, CO, USA \\ ${ }^{5}$ Air Quality Research Division, Science and Technology Branch, Environment Canada, Toronto, Ontario, Canada
}

Correspondence to: C. G. Nolte (nolte.chris@epa.gov)

Received: 18 April 2015 - Published in Geosci. Model Dev. Discuss.: 19 May 2015

Revised: 29 August 2015 - Accepted: 1 September 2015 - Published: 15 September 2015

\begin{abstract}
This work evaluates particle size-composition distributions simulated by the Community Multiscale Air Quality (CMAQ) model using micro-orifice uniform deposit impactor (MOUDI) measurements at 18 sites across North America. Size-resolved measurements of particulate $\mathrm{SO}_{4}^{2-}$, $\mathrm{NO}_{3}^{-}, \mathrm{NH}_{4}^{+}, \mathrm{Na}^{+}, \mathrm{Cl}^{-}, \mathrm{Mg}^{2+}, \mathrm{Ca}^{2+}$, and $\mathrm{K}^{+}$are compared to CMAQ model output for discrete sampling periods between 2002 and 2005. The observation sites were predominantly in remote areas (e.g., National Parks) in the USA and Canada, and measurements were typically made for a period of roughly 1 month. For $\mathrm{SO}_{4}^{2-}$ and $\mathrm{NH}_{4}^{+}$, model performance was consistent across the USA and Canadian sites, with the model slightly overestimating the peak particle diameter and underestimating the peak particle concentration compared to the observations. $\mathrm{Na}^{+}$and $\mathrm{Mg}^{2+}$ size distributions were generally well represented at coastal sites, indicating reasonable simulation of emissions from sea spray. CMAQ is able to simulate the displacement of $\mathrm{Cl}^{-}$in aged sea spray aerosol, though the extent of $\mathrm{Cl}^{-}$depletion relative to $\mathrm{Na}^{+}$is often underpredicted. The model performance for $\mathrm{NO}_{3}^{-}$exhibited much more site-to-site variability than that of $\mathrm{SO}_{4}^{2-}$ and $\mathrm{NH}_{4}^{+}$, with the model ranging from an underestimation to overestimation of both the peak diameter and peak particle concentration across the sites. Computing $\mathrm{PM}_{2.5}$ from the modeled size distribution parameters rather
\end{abstract}

than by summing the masses in the Aitken and accumulation modes resulted in differences in daily averages of up to $1 \mu \mathrm{g} \mathrm{m}^{-3}(10 \%)$, while the difference in seasonal and annual model performance compared to observations from the Interagency Monitoring of Protected Visual Environments (IMPROVE), Chemical Speciation Network (CSN), and Air Quality System (AQS) networks was very small. Two updates to the CMAQ aerosol model - changes to the assumed size and mode width of emitted particles and the implementation of gravitational settling - resulted in small improvements in modeled size distributions.

\section{Introduction}

A detailed understanding of the size, chemical composition, and atmospheric concentration of particulate matter (PM) is needed to assess its effects on human health, visibility, ecosystems, and climate. Assessments of these various PM effects are typically done with numerical models, and our confidence in the models is established through rigorous evaluation against ambient measurements. The mass concentration, size distribution, and bulk chemical composition of atmospheric PM are most often measured separately, and models are typically evaluated against these independent 
measures (e.g., Simon et al., 2012). However, it is well established that the PM composition varies considerably with particle size, and these size-resolved chemical characteristics govern the optical and radiative properties of PM. Because the aerodynamic behavior of PM is also a strong function of particle size, the size distributions of different chemical components also influence the human health and environmental effects of PM by affecting where particles are deposited in the respiratory tract (Asgharian et al., 2001) or whether they are transported to sensitive ecosystems (Scheffe et al., 2014).

Inertial cascade impactors are the most robust devices for collecting size-resolved ambient particles and analyzing their chemical composition (e.g., Marple et al., 1991). Because operating a cascade impactor is labor intensive and costly, their use has been restricted historically to field studies at individual locations or multi-site campaigns within small geographic regions (e.g., Herner et al., 2005). Previously, sizecomposition distributions simulated by the Community Multiscale Air Quality (CMAQ) model were evaluated against micro-orifice uniform deposit impactor (MOUDI) measurements of inorganic particle components at three coastal urban sites in Tampa, Florida, during May 2002 using CMAQ's standard modal aerosol formulation (Kelly et al., 2010) and a sectional formulation (Nolte et al., 2008). Kelly et al. (2011) evaluated size-composition distributions of inorganic and carbonaceous PM against MOUDI data at five sites in the Central Valley of California, as well as Bodega Bay and Sequoia during a wintertime episode. Also, Zhang et al. (2006) evaluated CMAQ predictions of total particle volume distributions in Atlanta, and Elleman and Covert (2010) evaluated predictions of total particle mass in two sub-micron size ranges in the Pacific Northwest. These studies indicate that CMAQ often overpredicts the peak diameter of PM masssize distributions and the widths of the lognormal particle modes. Kelly et al. (2011) reported that in some urban areas (e.g., Fresno, California), CMAQ adequately predicted the observed peak diameter for inorganic components but overpredicted the peak diameter of the organic and elemental carbon distributions. Overpredictions of particle diameter were found to lead to underpredictions of the PM mass in the sub$2.5 \mu \mathrm{m}$ size range $\left(\mathrm{PM}_{2.5}\right)$.

The scarcity of impactor data has prevented any model evaluation of size-composition distributions across a continental-scale domain. Such an evaluation would enhance our confidence in models for assessing the human health and ecosystem effects of PM. From 2001 to 2005, two field campaigns were conducted on a large geographic scale to yield size-segregated impactor measurements of the inorganic PM composition at 14 rural sites across the USA and Canada (Lee et al., 2008a; Zhang et al., 2008). In this paper, we evaluate size-composition distributions modeled by CMAQ against impactor measurements collected during these two campaigns, as well as urban-scale campaigns conducted in Pittsburgh and Tampa. We identify the regions and seasons where model performance is best as well as those where further model development is needed. Some implications on future evaluations of CMAQ output against routine measurements of $\mathrm{PM}_{2.5}$ composition are also discussed.

\section{Data}

\subsection{Model simulations}

The measurements used in this study were taken during discrete sampling periods within field campaigns spread across the years 2001-2005; therefore, several years of model simulations were required in order to create a comprehensive analysis data set. In all, 4 years of meteorology and air quality simulations were conducted, covering the period 20022005. The Weather Research and Forecasting (WRF; Skamarock and Klemp, 2008) model version 3.3 simulated meteorology over the contiguous USA and southern Canada with $12 \mathrm{~km} \times 12 \mathrm{~km}$ horizontal grid spacing. A terrain-following sigma vertical coordinate was used, with 35 vertical layers extending up to $50 \mathrm{hPa}$, and the top of the lowest model layer at approximately $20 \mathrm{~m}$. The WRF simulations were performed using the Pleim-Xiu land-surface model (PXLSM; Pleim and Xiu, 1995), the ACM2 planetary boundary layer (PBL) scheme (Pleim, 2007a, b), the Kain-Fritsch cumulus parameterization scheme (Kain, 2004), the Morrison microphysics scheme (Morrison et al., 2009), and fourdimensional data assimilation with no nudging in the PBL. Version 4.0 of the Meteorology-Chemistry Interface Processor (MCIP v4.0; Otte and Pleim, 2010) was used to prepare WRF outputs for CMAQ using the same 35-layer vertical structure as in WRF.

The CMAQ model configuration was the same for all simulations, with the only differences being in the yearspecific emission and meteorological input data. Aerosols in CMAQ are represented using three lognormal modes Aitken, accumulation, and coarse (Binkowski and Roselle, 2003). Inorganic species in the Aitken and accumulation modes are assumed to be in thermodynamic equilibrium with the gas phase, while gas-particle partitioning between the gas phase and the coarse mode is treated dynamically (Kelly et al., 2010). The secondary organic aerosol formulation in CMAQ has been described by Carlton et al. (2010). The simulations in this study used CMAQ version 5.0.1 with the AERO6 aerosol module, which includes speciation of trace metals (Reff et al., 2009; Appel et al., 2013) and sourcespecific ratios of organic mass to organic carbon (Simon and Bhave, 2012), and incorporates version II of the ISORROPIA thermodynamic equilibrium module (Fountoukis and Nenes, 2007). Other CMAQ model options employed include online computation of photolysis rates (Foley et al., 2010), a carbon bond chemical mechanism modified to include toluene and chlorine chemistry (CB05TUCL; Sarwar et al., 2011), and $\mathrm{NH}_{3}$ bi-directional surface exchange (Bash et al., 2013). Lateral boundary conditions (BCs) for the CMAQ simulations 
Table 1. Summary of the MOUDI data used in this study.

\begin{tabular}{|c|c|c|c|c|c|c|}
\hline Code & Location & Comment & Lat. $\mathrm{N}$ & Long. W & Dates & Ref.* \\
\hline ALG1 & Algoma, ON & moderately & 47.04 & 84.38 & 08-27 Feb 2003 & $\mathrm{a}$ \\
\hline ALG2 & & polluted & & & 05-26 Jun 2003 & \\
\hline AZP & Azalea Park, FL & urban coastal & 27.78 & 82.74 & 04 May-2 Jun 2002 & $\mathrm{~b}$ \\
\hline BON & Bondville, IL & agricultural & 40.05 & 88.37 & 01-27 Feb 2003 & $\mathrm{c}$ \\
\hline BRL & Bratt's Lake, SK & $\begin{array}{l}\text { polluted } \\
\text { agricultural }\end{array}$ & 50.20 & 104.20 & 11 Feb-04 Mar 2005 & $\mathrm{a}$ \\
\hline BRG & Brigantine, $\mathrm{NJ}$ & $\begin{array}{l}\text { coastal } \\
\text { wildlife refuge }\end{array}$ & 39.46 & 74.45 & 4-30 Nov 2003 & $\mathrm{c}$ \\
\hline CHA1 & Chalk River, ON & moderately & 46.06 & 77.40 & 22 Jan-21 Feb 2004 & $\mathrm{a}$ \\
\hline CHA2 & & polluted & & & 04-26 Jun 2004 & \\
\hline EGB & Egbert, ON & $\begin{array}{l}\text { polluted } \\
\text { agricultural }\end{array}$ & 44.23 & 79.78 & 06-13 Mar 2002 & $\mathrm{a}$ \\
\hline FRS & Frelighsberg, QC & $\begin{array}{l}\text { polluted } \\
\text { rural foothills }\end{array}$ & 45.05 & 73.06 & 04-16 May 2002 & a \\
\hline GAN & Gandy Bridge, FL & urban coastal & 27.97 & 82.23 & 04 May-02 Jun 2002 & $\mathrm{~b}$ \\
\hline GRC & Grand Canyon, AZ & remote & 35.97 & 111.98 & 01-30 May 2003 & $\mathrm{c}$ \\
\hline GSM & Great Smokies, TN & mountainous & 35.63 & 83.94 & 22 Jul-19 Aug 2004 & $\mathrm{c}$ \\
\hline KEJ1 & Kejimkujik, NS & clean coastal & 44.43 & 65.21 & 29 June-15 Jul 2002 & $\mathrm{a}$ \\
\hline KEJ2 & & & & & 25 Oct-15 Nov 2003 & \\
\hline LED1 & Lac Édouard, QC & clean & 47.68 & 72.44 & 11-27 Aug 2003 & $\mathrm{a}$ \\
\hline LED2 & & continental & & & 17 Oct-03 Nov 2003 & \\
\hline PIT & Pittsburgh, PA & urban & 40.44 & 79.94 & 01-17 Jan 2002 & $\mathrm{~d}$ \\
\hline SGO1 & San Gorgonio, CA & mountainous & 34.19 & 116.90 & 04-26 May 2003 & $\mathrm{c}$ \\
\hline $\mathrm{SGO} 2$ & & & & & 01-30 Jul 2003 & \\
\hline SPR1 & Sprucedale, ON & moderately & 45.42 & 79.49 & 17 Aug-18 Sep 2004 & $\mathrm{a}$ \\
\hline SPR2 & & polluted & & & 16 Nov-12 Dec 2004 & \\
\hline SYD & Sydney, FL & urban coastal & 27.97 & 82.23 & 04 May-02 Jun 2002 & $\mathrm{~b}$ \\
\hline YOS & Yosemite CA & mountainous & 37.75 & 119.59 & 15 Jul-02 Sep 2004 & $\mathrm{c}$ \\
\hline
\end{tabular}

* a: Zhang et al. (2008); b: Evans et al. (2004); c: Lee et al. (2008a); d: Cabada et al. (2004).

were obtained from monthly median concentrations from a GEOS-Chem (Bey et al., 2001) model simulation of the year 2005 (the same BCs were used for all 4 years) using the procedure described by Henderson et al. (2014).

Hourly, gridded emission data from non-mobile sources between 2002 and 2005 were created using version 3.1 of the Sparse Matrix Operator Kernel Emissions (SMOKEv3.1; Houyoux et al., 2000) model and are based on the $2002 \mathrm{Na}-$ tional Emissions Inventory (NEI) for the years 2002-2004 (2003 and 2004 are projected from 2002) and the 2005 NEI for 2005. Continuous emission monitoring (CEM) data were used for the electric generating units sector. Wildfire emissions were based on daily fire detections from the Hazard Mapping System and the Sonoma Technology SMARTFIRE system (Raffuse et al., 2009).

Hourly mobile emissions were created using year-specific traffic and meteorological data in version 2010b of the Motor Vehicle Emission Simulator (MOVESv2010b; http://www. epa.gov/otaq/models/moves). $\mathrm{PM}_{2.5}$ emissions of eight trace metals, including $\mathrm{Mg}^{2+}, \mathrm{Ca}^{2+}$, and $\mathrm{K}^{+}$, were speciated using the profiles in Reff et al. (2009). Other model configuration options affecting emissions include online emissions of accumulation- and coarse-mode $\mathrm{Na}^{+}, \mathrm{Cl}^{-}, \mathrm{SO}_{4}^{2-}, \mathrm{Mg}^{2+}$, $\mathrm{Ca}^{2+}$, and $\mathrm{K}^{+}$from sea spray (Kelly et al., 2010); online $\mathrm{NO}$ emissions using lightning flash counts from the National Lightning Detection Network (NLDN; Allen et al., 2012); Biogenic Emissions Landuse Database (BELD3) land use for gridded fractional crop distributions; version 3.1.4 of the Biogenic Emissions Inventory System (BEIS v3.1.4; Vukovich and Pierce, 2002) for online biogenic emissions; the 2001 version of the National Land Characterization Database (NLCD) for land use data; and $\mathrm{NH}_{3}$ emissions from fertilizer based on an Environmental Policy Integrated Climate (EPIC; Cooter et al., 2012) simulation using 2002 fertilizer sales data.

\subsection{MOUDI measurements}

The MOUDI measurements used in this study are from four distinct data sets, with one data set consisting of observations from wilderness sites located in several Canadian provinces (Zhang et al., 2008), another set consisting of sites primarily located in US National Parks (Malm et al., 2005; Lee et al., 2008a), a smaller data set from sites available during 


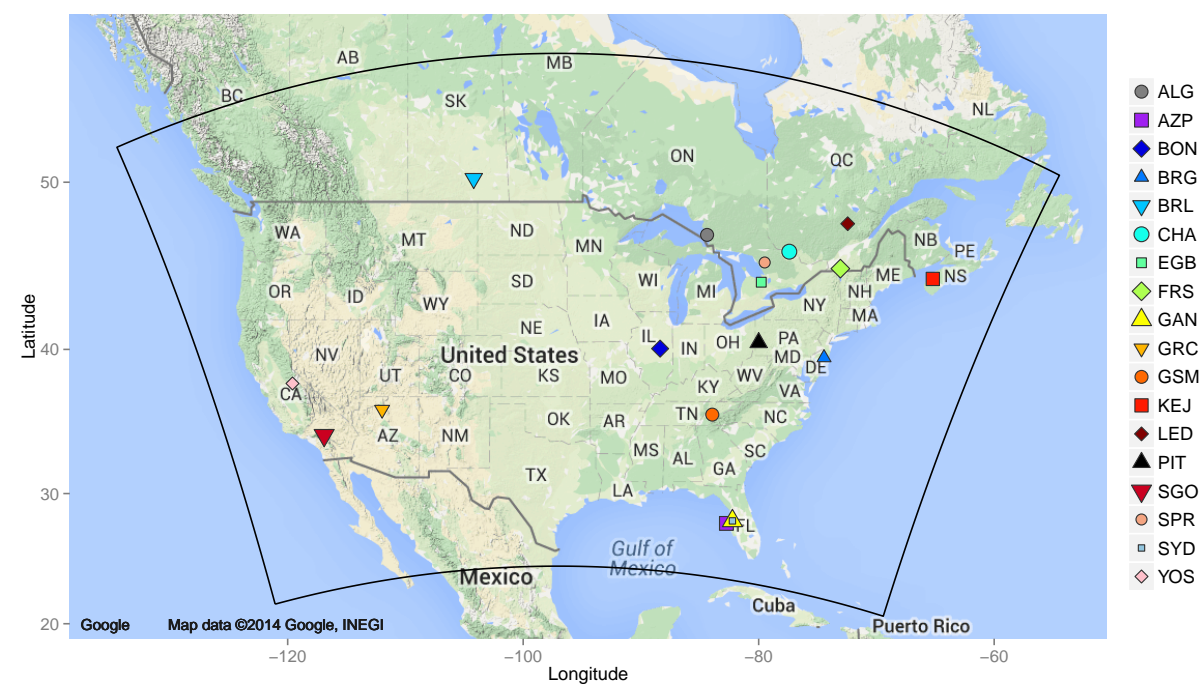

Figure 1. Locations of the sampling sites used in this study. See Table 1.

the Bay Region Atmospheric Chemistry (BRACE) study in Tampa, Florida (Evans et al., 2004), and finally a data set collected during the Pittsburgh Air Quality Study (Cabada et al., 2004). Data are available from 18 distinct sites covering 24 observation periods generally ranging in length from 2 to 4 weeks and covering each season of the year. To our knowledge, this collection represents the most comprehensive data set collected to date characterizing inorganic PM size-composition distributions for multiple locations across the USA and Canada and under diverse meteorological conditions. A brief description of the MOUDI data is provided below and a summary of the site locations and observation dates is provided in Table 1, with locations illustrated in Fig. 1.

Aerosol ion $\mathrm{SO}_{4}^{2-}, \mathrm{NO}_{3}^{-}, \mathrm{NH}_{4}^{+}, \mathrm{Cl}^{-}, \mathrm{Na}^{+}, \mathrm{Mg}^{2+}, \mathrm{Ca}^{2+}$, and $\mathrm{K}^{+}$) size distributions were measured at eight Canadian sites (i.e., ALG, BRL, CHA, EGB, FRS, KEJ, LED and SPR) (Zhang et al., 2008). The number of samples and the sample duration varied among monitors, with 7 being the fewest and 24 being the most samples taken during any one observation period, while the shortest sample duration was $6 \mathrm{~h}$ and the longest $152 \mathrm{~h}$. Standard ion chromatography was used for analyses of all filters after extraction in deionized water. Additional details regarding these measurements can be found in Zhang et al. (2008).

Size distributions of the same particle ions were collected at the BON, SGO, GRC, GSM, YOS, and BRG sites in the USA. To ensure adequate mass collection at these rural locations, samples were typically collected over a $48 \mathrm{~h}$ period, with the exception of Yosemite, which used $24 \mathrm{~h}$ sampling periods. A total of seven study periods are available from these sites in 2002-2004, with one study period in 2002 from mid-July to mid-August (YOS), five study periods in 2003 occurring in February (BON), April (SGO1), May (GRC),
July (SGO2), and November (BRG), and one study period in 2004 from mid-July to mid-August (GSM). Additional details regarding these data can be found in Lee et al. (2008a).

Aerosol ion size distributions in three urban locations were collected during the BRACE study in Florida in 2002 at the AZP, GAN, and SYD sites and in PIT in January 2002 (Table 1). Similar to the other two data sets described above, the BRACE data were collected using MOUDI samplers with 8 or 10 fractionation stages, an inlet height of $2 \mathrm{~m}$, and a flow rate of $30 \mathrm{~L} \mathrm{~min}^{-1}$ for sample durations of approximately $23 \mathrm{~h}$. Samples were collected on 15 days at the AZP and GAN sites and 14 days at the SYD site between 4 May and 2 June for a total of 58 samples. Samples at the Pittsburgh site were collected during 1-17 January for a total of 11 samples. Additional details regarding the BRACE data can be found in Evans et al. (2004) and Nolte et al. (2008), while additional details on the Pittsburgh data can be found in Cabada et al. (2004) and Stanier et al. (2004).

\subsection{Data pairing and analysis}

The particle size distribution data consist of multiple measurements taken over a period of several weeks. Since the analysis is focused on broad persistent features rather than day-to-day variability, the data here are averaged into a single observed and modeled size distribution for each ion for each campaign listed in Table 1 , where the model output is averaged over the days and times corresponding to each sampling period. The CMAQ aerosol model uses three lognormal modes (Aitken, accumulation, and coarse) to represent particle size distributions (Binkowski and Roselle, 2003), whereas the observations are separated into discrete size bins. To facilitate comparison between the model and the observations, the three modes in the model are summed to produce a single smooth curve. For each mode $(j)$, mass 

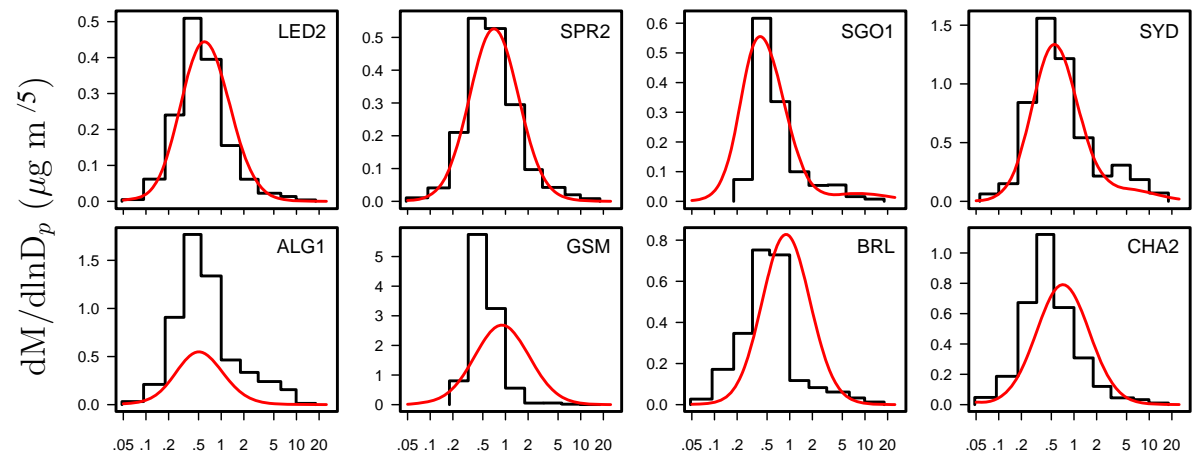

Aerodynamic diameter $(\mu \mathrm{m})$

Figure 2. Average observed (black) and modeled (red) $\mathrm{SO}_{4}^{2-}$ size distributions at representative sites.

concentrations $\left(M_{j}=\sum_{i} M_{i j}\right)$ are obtained from the CMAQ hourly average concentration (ACONC) files, where $M_{i j}$ is the mass of constituent $i$ in mode $j$. "Wet" (i.e., including aerosol water) modal parameters $D_{\mathrm{g}, j}, \sigma_{\mathrm{g}, j}$, and $M_{3, j}$ are taken from the aerosol diagnostic (AERODIAM) output files, where $D_{\mathrm{g}, j}$ is the geometric number mean diameter of mode $j, \sigma_{\mathrm{g}, j}$ is the geometric standard deviation of mode $j$, and $M_{3, j}$ is the third moment of mode $j$. Particle densities $\rho_{j}$ $\left(\mathrm{g} \mathrm{cm}^{-3}\right)$ are calculated as

$\rho_{j}=\frac{10^{-12}}{M_{3, j}} \frac{6}{\pi} M_{j}$

The geometric volume mean diameters $D_{\mathrm{gv}}$ are calculated from the number mean diameters using the Hatch-Choate relation

$D_{\mathrm{gv}, j}=D_{\mathrm{g}, j} \exp \left(3 \ln ^{2} \sigma_{\mathrm{g}, j}\right)$.

The size distribution at each hour $t$ is then computed as

$$
\begin{aligned}
\frac{\mathrm{d} M}{\mathrm{~d} \ln D_{\mathrm{pa}}}\left(D_{\mathrm{pa}}, t\right) & =\sum_{j=1}^{3} \frac{M_{j}}{\sqrt{2 \pi} \ln \sigma_{\mathrm{g}, j}} \\
& \exp \frac{-\left(\ln D_{\mathrm{pa}}-\frac{1}{2} \ln \rho_{j}-\ln D_{\mathrm{gv}, j}\right)^{2}}{2 \ln ^{2} \sigma_{\mathrm{g}, j}},
\end{aligned}
$$

where the $\frac{1}{2} \ln \rho_{j}$ term accounts for using the aerodynamic diameter $D_{\mathrm{pa}}$ as the independent variable, to facilitate comparison with measured size distributions. The above equation is discretized by $\ln D_{\mathrm{pa}}$, and the discretized values are computed for each hour before finally computing the temporally averaged size distribution.

For Aitken and accumulation-mode species, the inputs to Eq. (3) are obtained directly from CMAQ outputs for the corresponding grid cell, but directly emitted coarse-mode species require special processing. In AERO6, accumulationmode emissions from sea spray are chemically speciated into $\mathrm{Na}^{+}, \mathrm{Cl}^{-}, \mathrm{SO}_{4}^{2-}, \mathrm{Mg}^{2+}, \mathrm{Ca}^{2+}$, and $\mathrm{K}^{+}$components, but coarse-mode sea spray cations are lumped into a single species, ASEACAT, for computational efficiency during transport. Similarly, anthropogenic coarse primary emissions are lumped into ACORS, and coarse windblown soil dust is modeled as ASOIL. Concentrations of individual chemical components in the coarse mode are computed from ASEACAT, ASOIL, and ACORS:

$$
\begin{aligned}
\text { ANAK } & =0.8373 \cdot \text { ASEACAT }+0.0626 \cdot \text { ASOIL } \\
& +0.0023 \cdot \text { ACORS } \\
\text { AMGK } & =0.0997 \cdot \text { ASEACAT }+0.0032 \cdot \text { ACORS } \\
\text { AKK } & =0.0310 \cdot \text { ASEACAT }+0.0242 \cdot \text { ASOIL } \\
& +0.0176 \cdot \text { ACORS } \\
\text { ACAK } & =0.0320 \cdot \text { ASEACAT }+0.0838 \cdot \text { ASOIL } \\
& +0.0562 \cdot \text { ACORS }
\end{aligned}
$$

In Eqs. (4)-(7), ANAK, AMGK, AKK, and ACAK are coarse mode $\mathrm{Na}^{+}, \mathrm{Mg}^{2+}, \mathrm{K}^{+}$, and $\mathrm{Ca}^{2+}$, respectively, and the coefficients are relative abundances in seawater and composite weighting factors based on profiles in the SPECIATE database (Simon et al., 2010).

\section{Evaluation of size distributions}

In this section CMAQ modeled size-composition distributions are compared to the MOUDI measurements. For brevity, a few representative sites and time periods are presented for each ion. Plots of the average modeled and measured size distributions for all 24 campaigns listed in Table 1 are available in the Supplement for each of the inorganic ions analyzed.

\section{1 $\mathrm{SO}_{4}^{2-}$ and $\mathrm{NH}_{4}^{+}$}

Modeled and observed $\mathrm{SO}_{4}^{2-}$ size distributions at each site and averaged over each sampling campaign are shown in Supplement Fig. S1. The model generally captures the variability in the $\mathrm{SO}_{4}^{2-}$ size distribution across different sites 

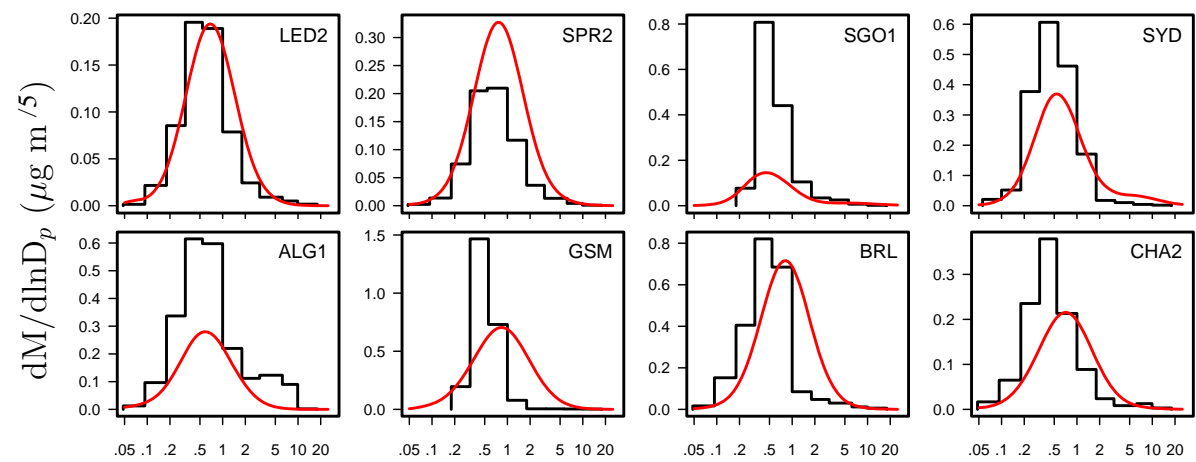

Aerodynamic diameter $(\mu \mathrm{m})$

Figure 3. Average observed (black) and modeled (red) $\mathrm{NH}_{4}{ }^{+}$size distributions at representative sites.
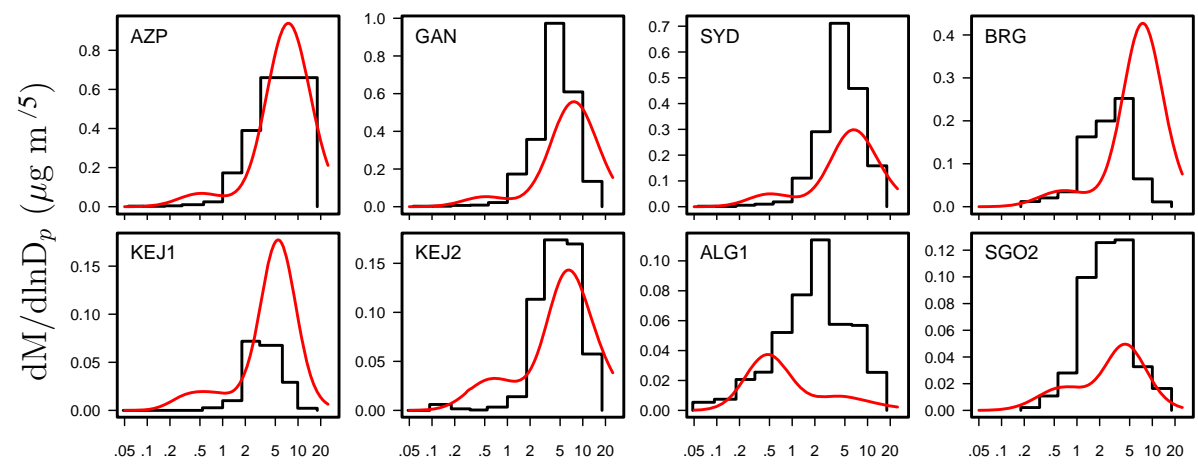

Aerodynamic diameter $(\mu \mathrm{m})$

Figure 4. Average observed (black) and modeled (red) $\mathrm{Na}^{+}$size distributions at representative sites.

and different seasons. As shown in Fig. 2, the model accurately reproduces the observed $\mathrm{SO}_{4}^{2-}$ size distribution at many sites, including LED2, SPR2, SGO1, and SYD. However, the model fails to capture the accumulation-mode peak observed in many of the campaigns (e.g., ALG1 and GSM), and often the modeled peak diameter is shifted to larger sizes (e.g., BRL and CHA2) than indicated by the measurements.

The model performance for particle $\mathrm{NH}_{4}^{+}$(Fig. 3 and Supplement Fig. S2) generally follows that of $\mathrm{SO}_{4}^{2-}$, with the model tending to underestimate the accumulation-mode peak concentration and overestimating the aerodynamic diameter where the peak occurs. Modeled and observed $\mathrm{NH}_{4}^{+}$size distributions are generally in good agreement at those sites where $\mathrm{SO}_{4}^{2-}$ performance is best (i.e., LED2, SPR2, and SYD), though there is a large $\mathrm{NH}_{4}^{+}$underprediction at SGO1 in contrast to good $\mathrm{SO}_{4}^{2-}$ performance there. This behavior is consistent with recent studies that have reported that $\mathrm{NH}_{3}$ emissions in southern California's South Coast Air Basin are underestimated in the NEI (Nowak et al., 2012; Kelly et al., 2014). Similarly to the performance for $\mathrm{SO}_{4}^{2-}$, the model largely underestimates the $\mathrm{NH}_{4}^{+}$accumulation-mode peak and overestimates the diameter at which the peak occurs at ALG1, GSM, BRL, and CHA2.

\section{2 $\mathrm{Na}^{+}$and $\mathrm{Cl}^{-}$}

Sea spray is the principal source of $\mathrm{Na}^{+}$and, at most locations, the dominant source of $\mathrm{Cl}^{-}$as well. Average modeled and observed $\mathrm{Na}^{+}$size distributions are plotted for the coastal and near-coastal sites in Fig. 4. $\mathrm{Cl}^{-}$size distributions generally follow those for $\mathrm{Na}^{+}$and accordingly they are not further discussed here, though $\mathrm{Na}^{+}$and $\mathrm{Cl}^{-}$plots across all the campaigns are presented in Supplement Figs. S3 and S4. CMAQ generally captures the $\mathrm{Na}^{+}$size distributions and elevated concentrations at the coastal sites, i.e., the BRACE sites (AZP, GAN, and SYD), as well as BRG and KEJ. At most of the other sites, $\mathrm{Na}^{+}$concentrations are very low; often concentrations at these sites are near the detection limit, and confidence in the measurements is relatively low (Zhang et al., 2008). CMAQ correctly simulates that $\mathrm{Na}^{+}$concentrations are low at these low-concentration sites, though size distributions do not agree very well with measurements (Supplement Fig. S3). The ALG site near Lake Superior is not impacted by sea spray; the relatively high $\mathrm{Na}^{+}$concentrations in ALG1 are due to the application of salt to roads to prevent ice formation during the winter (Zhang et al., 2008). As this Canadian road salt is not in the US NEI, it is not surprising 

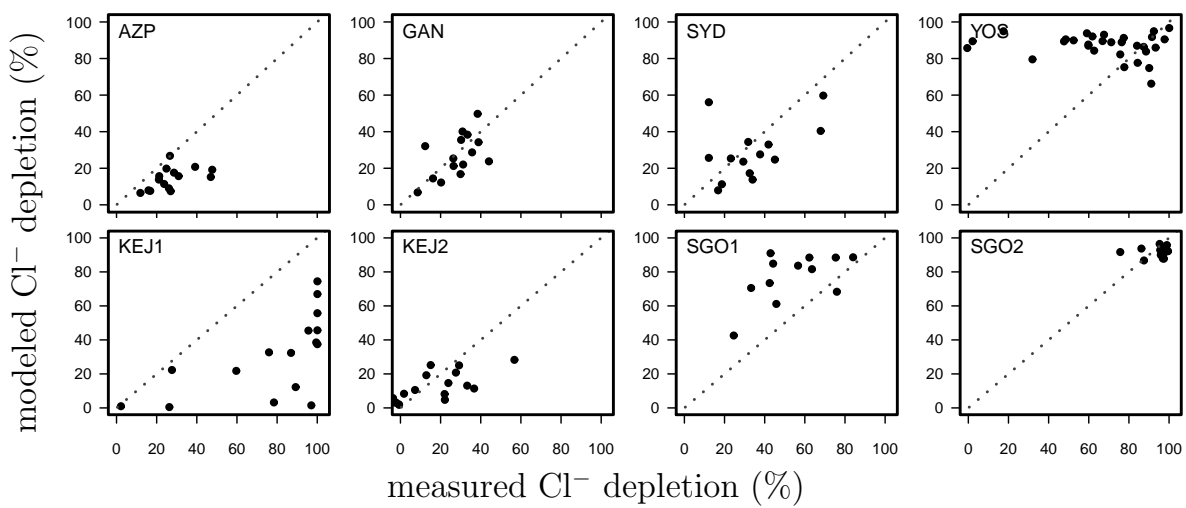

Figure 5. Scatter plots of modeled and observed chloride depletion in coarse $\left(D_{\mathrm{p}}>2.5 \mu \mathrm{m}\right)$ particles at representative sites. Each point represents a distinct measurement period, with modeled concentrations averaged over the corresponding intervals.

that the model is unable to capture this peak. SGO is in a mountainous wilderness area about $100 \mathrm{~km}$ from the Pacific Ocean. Because simulating winds over mountainous terrain is challenging, particularly with $12 \mathrm{~km}$ grid cells, CMAQ's relatively poor performance for $\mathrm{Na}^{+}$at SGO2 is likely attributable to errors in transport to the SGO site.

The concentration of $\mathrm{Cl}^{-}$in fresh sea spray aerosol is proportional to its abundance in seawater. While $\mathrm{Na}^{+}$and other sea salt cations are chemically inert, under certain conditions $\mathrm{Cl}^{-}$in aged sea spray particles can be displaced by condensed gas-phase acids, such as $\mathrm{HNO}_{3}$. The percentage of chloride depleted can be defined as (Yao and Zhang, 2012)

$\mathrm{Cl}_{\text {depletion }}^{-}(\%)=\frac{\alpha\left[\mathrm{Na}^{+}\right]-\left[\mathrm{Cl}^{-}\right]}{\alpha\left[\mathrm{Na}^{+}\right]} \times 100$,

where $\left[\mathrm{Na}^{+}\right]$and $\left[\mathrm{Cl}^{-}\right]$are molar equivalent concentrations and $\alpha$ is the ratio of the relative molar abundance of $\mathrm{Cl}^{-}$ to $\mathrm{Na}^{+}$in seawater, equal to 1.164 in CMAQ. The modeled percentages of chloride depletion are compared to the individual measurements at near-coastal sites in Fig. 5. Consistent with previous results of Kelly et al. (2010), the model frequently underestimates the moderate $(25-50 \%)$ levels of chloride depletion seen at the BRACE sites (AZP, GAN, and SYD), which are within $20 \mathrm{~km}$ or less from Tampa Bay. The negative bias in the amount of chloride depletion is slightly greater at BRG (not shown). For the rural coastal KEJ site in Nova Scotia, the model slightly underestimates the chloride depletion during the fall campaign (KEJ2), but severely underestimates the frequently near-total depletion observed during the summer (KEJ1) (Yao and Zhang, 2012). For the springtime campaign SGO1, the modeled $\mathrm{Cl}^{-}$depletion is overestimated. There are significant contributions of sodium from the primary species ASOIL and ACORS for SGO1, which could be contributing to an overprediction of $\mathrm{Na}^{+}$ and hence an overprediction of $\mathrm{Cl}^{-}$depletion. For the summer SGO2 campaign, the model correctly simulates chloride depletions approaching $100 \%$, while at YOS the modeled degree of chloride depletion is sometimes greater than ob- served. Highly time-resolved measurements were made using a particle-into-liquid sampler (PILS) at the same locations and times as the MOUDI measurements that are the focus of this study (Lee et al., 2008b). The PILS measurements show that $\mathrm{NO}_{3}^{-}$peaks coincide with $\mathrm{Cl}^{-}$dropping below detection limits at YOS and $\mathrm{SGO} 2$, providing strong evidence of chloride displacement from condensation of $\mathrm{HNO}_{3}$. The PILS data further demonstrate that aerosol concentrations varied substantially on much shorter timescales than could be captured by the integrated MOUDI measurements, which are subject to volatilization losses during sampling, particularly in the summer (Lee, 2007; Lee et al., 2008a).

\section{3 $\mathrm{Mg}^{2+}, \mathrm{Ca}^{2+}$, and $\mathrm{K}^{+}$}

At coastal sites, modeled $\mathrm{Mg}^{2+}$ concentrations generally follow modeled $\mathrm{Na}^{+}$concentrations in accordance with their relative abundances in seawater, and model performance for $\mathrm{Mg}^{2+}$ generally follows that of $\mathrm{Na}^{+}$at these sites. At AZP (Fig. 6) as well as GAN, SYD, BRG, KEJ1, KEJ2, ALG1, and SGO2 (Supplement Fig. S6), the observed and modeled $\mathrm{Mg}^{2+}$ size distributions have the same relationship to each other as the corresponding $\mathrm{Na}^{+}$size distributions at those sites. At BRL, GRC, and YOS, $\mathrm{Mg}^{2+}$ is likely to have a crustal rather than oceanic origin. At these western sites, $\mathrm{Mg}^{2+}$ is underpredicted (Fig. 6), consistent with findings of Appel et al. (2013). Unlike the situation for $\mathrm{Mg}^{2+}$, the ratio of $\mathrm{Ca}^{2+}$ to $\mathrm{Na}^{+}$in the measurements at coastal sites is substantially greater than can be explained by their relative abundances in seawater (Fig. 6 and Supplement Fig. S7). This suggests that there is a source (most likely not originating from seawater) of $\mathrm{Ca}^{2+}$ at those sites that is either absent or is underrepresented by the model. On the other hand, modeled $\mathrm{Ca}^{2+}$ is higher than modeled $\mathrm{Mg}^{2+}$ at BRL, GRC, and YOS, in better agreement with observations, indicating that the coarse mode $\mathrm{Ca}^{2+}$ at those sites is due to contributions from anthropogenic fugitive dust or soils rather than sea spray. The chemical speciation of windblown dust and 


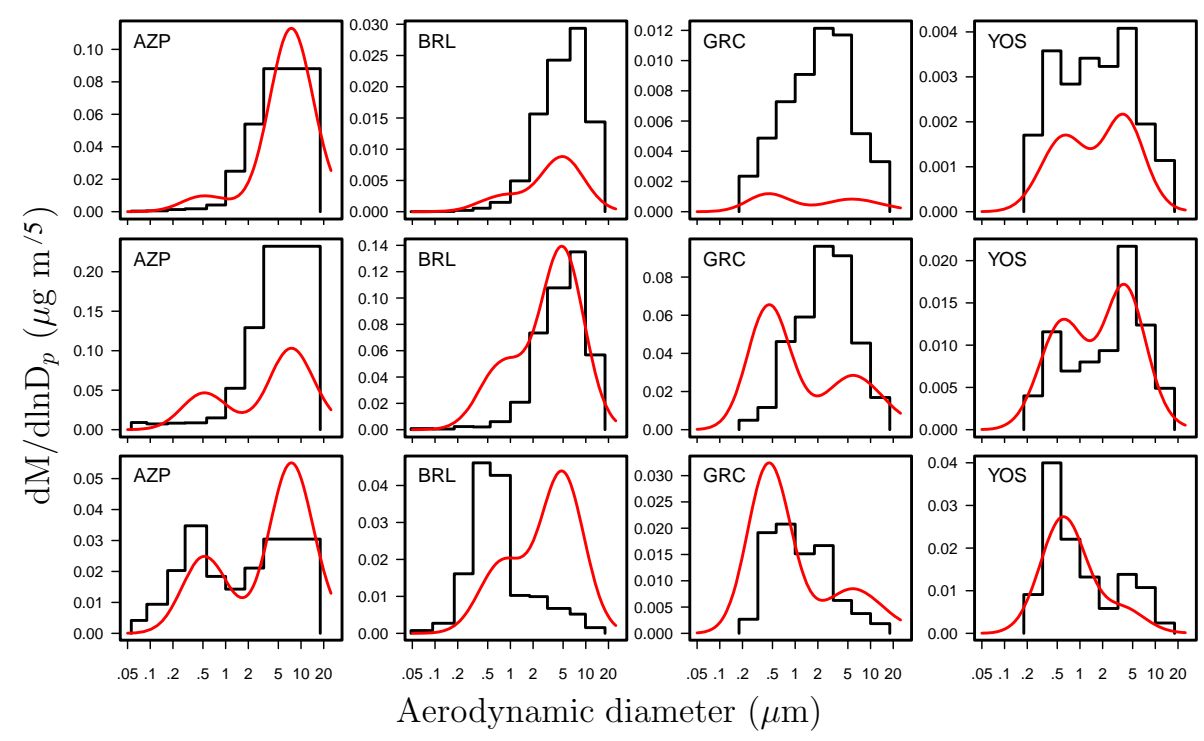

Figure 6. Average observed (black) and modeled (red) $\mathrm{Mg}^{2+}$ (top), $\mathrm{Ca}^{2+}$ (middle), and $\mathrm{K}^{+}$(bottom) size distributions at representative sites.
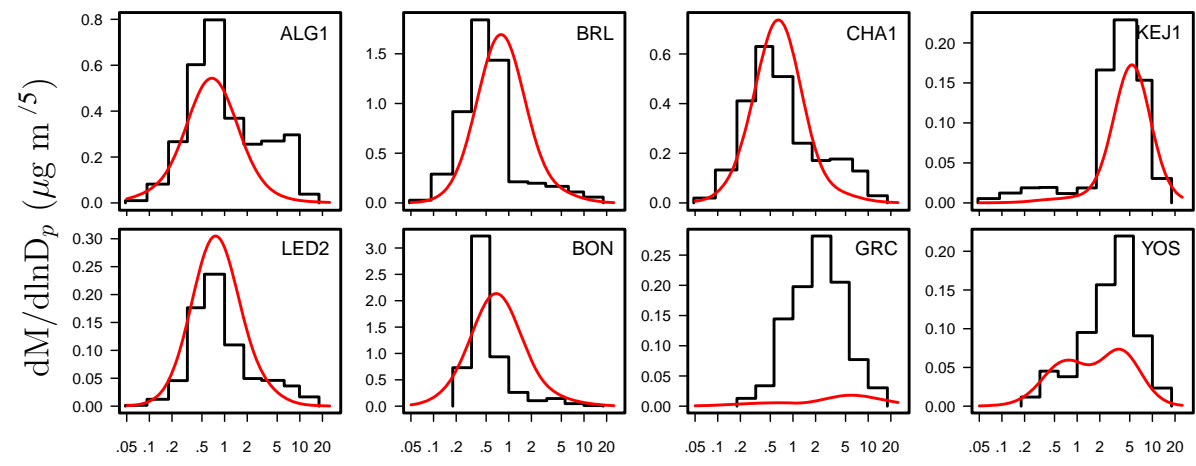

Aerodynamic diameter $(\mu \mathrm{m})$
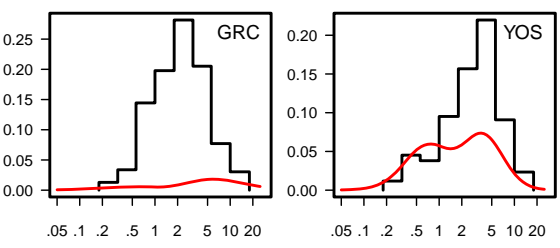

Figure 7. Average observed (black) and modeled (red) $\mathrm{NO}_{3}^{-}$size distributions at representative sites.

directly emitted coarse PM is derived from four California desert soil profiles in SPECIATE. Because these profiles did not report $\mathrm{Mg}$, these sources do not contribute to $\mathrm{Mg}^{2+}$ concentrations modeled by CMAQ. The relatively good model performance for $\mathrm{Ca}^{2+}$ and underprediction of $\mathrm{Mg}^{2+}$ at these sites suggest that the $\mathrm{Mg}^{2+}$ speciation factors for primary coarse PM and windblown dust should be revisited.

Model performance for $\mathrm{K}^{+}$is notably better than for $\mathrm{Ca}^{2+}$, with the model reasonably capturing the observed pattern at most sites (Fig. 6 and Supplement Fig. S7). $\mathrm{K}^{+}$is known to be emitted from biomass burning in addition to the sea spray and dust sources that also impact $\mathrm{Ca}^{2+}$. The impact of the combustion source of $\mathrm{K}^{+}$is evident in the smaller peak diameters for the $\mathrm{K}^{+}$than the $\mathrm{Mg}^{2+}$ and $\mathrm{Ca}^{2+}$ observed distributions. The model simulates a bimodal distribution at GRC where the observed distribution was a broad single mode, and the coarse mode is underpredicted at YOS. Overall, however, the model does well in simulating the observed $\mathrm{K}^{+}$particle distribution at the majority of the Canadian and USA sites.

\section{4 $\quad \mathrm{NO}_{3}^{-}$}

Aerosol $\mathrm{NO}_{3}^{-}$is formed almost entirely from condensation of gas-phase $\mathrm{HNO}_{3}$ on existing particles. Moreover, the degree of gas-particle mass transfer for nitrate is thermodynamically driven, and is a strong function of inorganic particle composition as well as temperature and relative humidity. As a result, the $\mathrm{NO}_{3}^{-}$size distribution depends on the distribution of other ions, especially $\mathrm{SO}_{4}^{2-}$ and $\mathrm{NH}_{4}^{+}$, making it particularly challenging to model accurately (Yu et al., 2005). $\mathrm{NO}_{3}^{-}$is also subject to measurement artifacts, including the loss of semivolatile ammonium nitrate from the MOUDI. Parallel measurements of $\mathrm{PM}_{2.5}$ nitrate made using denuder/filter-pack sampling trains designed to account for 

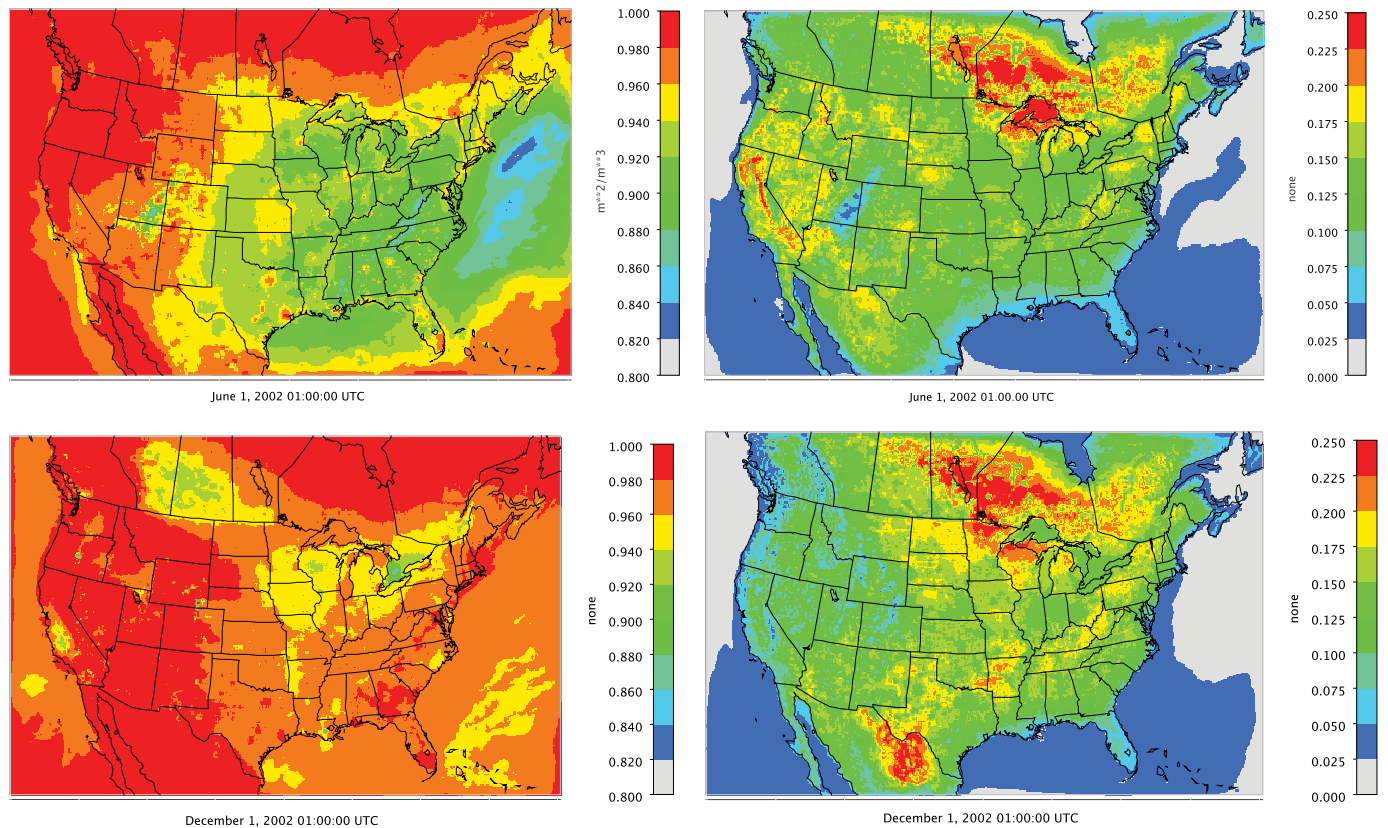

Figure 8. Fraction of accumulation mode (left) and coarse mode (right) smaller than $2.5 \mu \mathrm{m}$ in diameter, averaged over summer (top) and winter (bottom) 2002.

ammonium nitrate volatilization showed some loss of nitrate at most sites, but typically less than 20-30\% (Lee, 2007).

Model performance for $\mathrm{NO}_{3}^{-}$(Fig. 7 and Supplement Fig. S8) is generally good at ALG1, CHA1, and KEJ1, though the coarse mode is somewhat underpredicted at these sites, while the accumulation mode is slightly overpredicted at LED2. Despite the greater surface area of the fine modes, $\mathrm{NO}_{3}^{-}$often resides in the coarse mode when the fine modes are too acidic from condensation of $\mathrm{H}_{2} \mathrm{SO}_{4}$, which has lower vapor pressure than $\mathrm{HNO}_{3}$ under ambient conditions. At BRL and BON, the modeled size distribution is broader and shifted slightly to larger particles than measured by the MOUDI. At SGO1 and YOS, particle $\mathrm{NO}_{3}^{-}$is significantly underestimated. These errors in modeled $\mathrm{NO}_{3}^{-}$concentrations can be attributed to underestimated levels of accumulation-mode $\mathrm{NH}_{4}^{+}$at $\mathrm{SGO} 1$ and underestimated coarse-mode $\mathrm{Na}^{+}$at YOS (cf. Fig. 7 and Supplement Fig. S3).

\section{Modeled PM 2.5}

In the USA, air quality regulations for particulate matter are based on the total mass of particles (after equilibration to room temperature and low humidity) with aerodynamic diameters less than $2.5 \mu \mathrm{m}$ (Frank, 2006). Most CMAQ model evaluations, however (e.g., Appel et al., 2008), have used the sum of PM in the Aitken $(i)$ and accumulation $(j)$ modes (i.e., $\mathrm{PM}_{i j}$ ) to represent $\mathrm{PM}_{2.5}$. As noted by Jiang et al. (2006), $\mathrm{PM}_{i j}$ and $\mathrm{PM}_{2.5}$ are conceptually distinct quanti- ties that sometimes differ significantly. Since the release of CMAQ v4.5 in 2005, additional variables are output to an optional diagnostic file (i.e., AERODIAM) that facilitate a more explicit calculation of modeled $\mathrm{PM}_{2.5}$ based on the simulated size distribution. Despite this capability, $\mathrm{PM}_{i j}$ is still typically used for CMAQ model evaluation (Foley et al., 2010). As a further evaluation of CMAQ modeled aerosol size distributions, here we compare modeled $\mathrm{PM}_{2.5}$ to the traditional $\mathrm{PM}_{i j}$ calculations and to observed total $\mathrm{PM}_{2.5}$ from the Interagency Monitoring of Protected Visual Environments (IMPROVE), Chemical Speciation Network (CSN), and Air Quality System (AQS) networks for 2002.

The mass-weighted fractions of the accumulation mode and coarse mode in the $\mathrm{PM}_{2.5}$ size range averaged over the summer (June-August 2002) and winter (January, February, and December 2002) months are shown in Fig. 8. Although during the winter the vast majority of the accumulation mode is smaller than $2.5 \mu \mathrm{m}$, during the summer up to $10-12 \%$ of the accumulation mode is greater than $2.5 \mu \mathrm{m}$ in size. The smaller fraction of the accumulation mode in the $\mathrm{PM}_{2.5}$ size range in the eastern USA is attributable to larger amounts of aerosol water, both because of higher humidities and higher concentrations of hygroscopic $\mathrm{SO}_{4}^{2-}$. The fractional contribution of the coarse mode to $\mathrm{PM}_{2.5}$ is fairly uniform, ranging from 10 to $15 \%$, though there are a few areas where the contribution exceeds $20 \%$. Modeled $\mathrm{PM}_{2.5}$ is $0.3-1.2 \mu \mathrm{g} \mathrm{m}^{-3}$ lower than $\mathrm{PM}_{i j}$ across a large portion of the eastern USA during the summer (Fig. 9), primarily due to the greater contributions of $\mathrm{SO}_{4}^{2-}, \mathrm{NO}_{3}^{-}, \mathrm{NH}_{4}^{+}$, and elemental carbon (EC) to $\mathrm{PM}_{i j}$ than $\mathrm{PM}_{2.5}$ concentrations. In the 


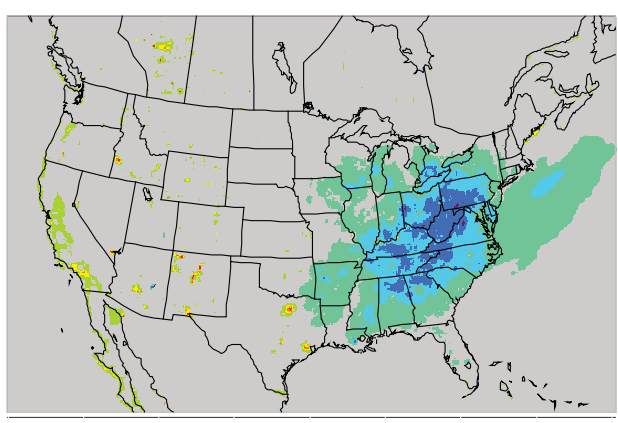

June 1, 2002 01:00:00 UTC

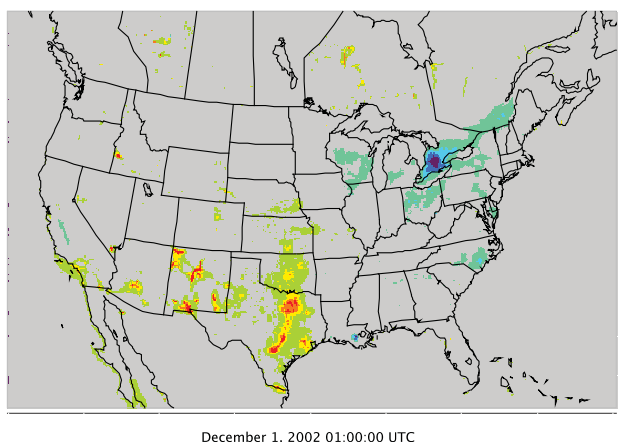

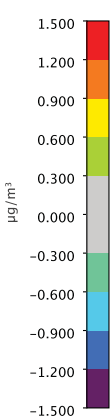
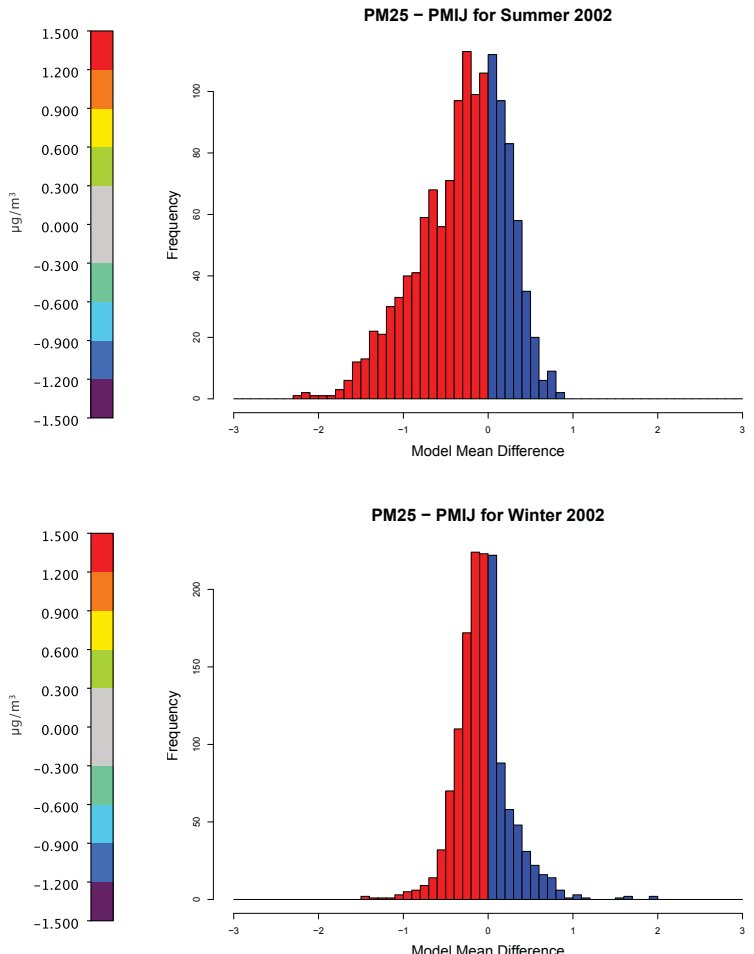

Figure 9. Difference between $\mathrm{PM}_{2.5}$ computed using modeled size distribution and $\mathrm{PM}_{i j}$, and histogram of daily average differences $\left(\mathrm{PM}_{2.5}-\mathrm{PM}_{i j}\right)$ for summer (top) and winter (bottom) 2002. Blue shading indicates days where $\mathrm{PM}_{2.5}$ is greater than $\mathrm{PM}_{i j}$, while red shading indicates days where $\mathrm{PM}_{2.5}$ is less than $\mathrm{PM}_{i j}$.

western USA, $\mathrm{PM}_{2.5}$ values are sporadically higher (primarily in Texas, New Mexico, Arizona, and southern California) due almost exclusively to the greater contributions of soil (i.e., $\mathrm{Al}, \mathrm{Si}, \mathrm{Ca}, \mathrm{Fe}$, and $\mathrm{Ti}$ ) to $\mathrm{PM}_{2.5}$ than $\mathrm{PM}_{i j}$ that result from the tail of the coarse mode overlapping the $\mathrm{PM}_{2.5}$ size range. The relative differences are $4-12 \%$ in the eastern USA during summer and 4-20\% in the western USA (Supplement Fig. S9).

Histograms of the difference in CMAQ daily mean aerosol concentrations (modeled $\mathrm{PM}_{2.5}$ - modeled $\mathrm{PM}_{i j}$ ) at IMPROVE, CSN, and AQS-FRM (Federal Reference Method) sites for 2002 are also shown in Fig. 9. The distribution of mean differences is predominantly negative, particularly during summer and fall (not shown), indicating that $\mathrm{PM}_{i j}$ is generally greater than $\mathrm{PM}_{2.5}$. For all seasons, the differences in $\mathrm{PM}_{2.5}$ and $\mathrm{PM}_{i j}$ typically fall between $\pm 1 \mu \mathrm{g} \mathrm{m}^{-3}$.

The mean bias (MB), mean error (ME) and root mean square error (RMSE) as computed against the IMPROVE, CSN and AQS-FRM observations using modeled $\mathrm{PM}_{2.5}$ and $\mathrm{PM}_{i j}$ values are provided in Table 2. The difference in network- and seasonally averaged MB, ME, and RMSE computed using $\mathrm{PM}_{2.5}$ and $\mathrm{PM}_{i j}$ is generally small. For winter, spring, and fall, average $\mathrm{PM}_{2.5}$ is $0.04-0.20 \mu \mathrm{g} \mathrm{m}^{-3}$ less than $\mathrm{PM}_{i j}$. Since the model is generally positively biased with respect to observations during those seasons, using $\mathrm{PM}_{2.5}$ rather than $\mathrm{PM}_{i j}$ results in slightly improved perfor- mance statistics. The difference between $\mathrm{PM}_{2.5}$ and $\mathrm{PM}_{i j}$ is larger (more negative) during the summer. Since the model is generally negatively biased during the summer, largely due to underpredictions of secondary organic aerosol (Carlton et al., 2010), the MB, ME, and RMSE are all slightly worse for $\mathrm{PM}_{2.5}$ than for $\mathrm{PM}_{i j}$. The differences during the summer are still small, however, averaging $0.30 \mathrm{\mu g} \mathrm{m}^{-3}$ for $\mathrm{MB}, 0.22 \mu \mathrm{g} \mathrm{m}^{-3}$ for ME, and $0.21 \mu \mathrm{g} \mathrm{m}^{-3}$ for RMSE. Overall, the aggregated model performance using modeled $\mathrm{PM}_{2.5}$ and $\mathrm{PM}_{i j}$ is nearly the same, with the average difference $\left(\mathrm{PM}_{2.5}-\mathrm{PM}_{i j}\right)$ in MB, ME, and RMSE across all seasons of $-0.15,0.02$, and $0.02 \mu \mathrm{g} \mathrm{m}^{-3}$, respectively. Therefore, while the difference between $\mathrm{PM}_{2.5}$ and $\mathrm{PM}_{i j}$ values for any particular observation site and time may be important, the difference in model performance between the two values is relatively small on average. The difference in the two methods for estimating $\mathrm{PM}_{2.5}$ is likely to be even smaller when the models are applied in a relative sense for a regulatory context (Baker and Foley, 2011).

In the version of CMAQ (v4.3) used by Jiang et al. (2006), there was very little mass in the coarse mode, and this mode was modeled as being chemically inert. Thus, $\mathrm{PM}_{i j}$ was always greater than $\mathrm{PM}_{2.5}$ in that version. Because the model was generally positively biased with respect to measurements, using the size distribution to compute $\mathrm{PM}_{2.5}$ improved model performance statistics. There 
Table 2. Comparison of CMAQ PM model performance relative to observations at IMPROVE, CSN, and AQS network sites during 2002 using the sum of masses in the Aitken and accumulation modes $\left(\mathrm{PM}_{i j}\right)$ and calculated using the modeled size distribution $\left(\mathrm{PM}_{2.5}\right)$.

\begin{tabular}{|c|c|c|c|c|c|c|c|c|c|}
\hline \multirow[b]{2}{*}{ Season } & \multicolumn{3}{|c|}{$\mathrm{MB}\left(\mu \mathrm{g} \mathrm{m}^{-3}\right)$} & \multicolumn{3}{|c|}{$\operatorname{ME}\left(\mu \mathrm{g} \mathrm{m}^{-3}\right)$} & \multicolumn{3}{|c|}{$\operatorname{RMSE}\left(\mu \mathrm{g} \mathrm{m}^{-3}\right)$} \\
\hline & $\mathrm{PM}_{2.5}$ & $\mathrm{PM}_{i j}$ & $\Delta^{*}$ & $\mathrm{PM}_{2.5}$ & $\mathrm{PM}_{i j}$ & $\Delta$ & $\mathrm{PM}_{2.5}$ & $\mathrm{PM}_{i j}$ & $\Delta$ \\
\hline Winter (DJF) & 2.38 & 2.42 & -0.04 & 5.19 & 5.28 & -0.09 & 8.68 & 8.73 & -0.05 \\
\hline Spring (MAM) & 0.46 & 0.53 & -0.07 & 3.64 & 3.65 & -0.01 & 6.07 & 6.11 & -0.04 \\
\hline Summer (JJA) & -3.60 & -3.30 & -0.30 & 5.85 & 5.63 & 0.22 & 9.90 & 9.69 & 0.21 \\
\hline Fall (SON) & 0.96 & 1.16 & -0.20 & 4.77 & 4.79 & -0.02 & 7.98 & 8.01 & -0.03 \\
\hline Average & 0.05 & 0.20 & -0.15 & 4.86 & 4.84 & 0.02 & 8.16 & 8.14 & 0.02 \\
\hline
\end{tabular}

have been several updates to the CMAQ aerosol model since the version used by Jiang et al. (2006). For this discussion, the most significant of these are the reduction of overestimated unspeciated $\mathrm{PM}_{2.5}$ (i.e., PMOTHER; Appel et al., 2008, 2013; Foley et al., 2010), and the treatment of gasparticle nitrate mass transfer to and from coarse-mode particles (Kelly et al., 2010). As a result, the consequence of estimating $\mathrm{PM}_{2.5}$ concentrations by using the modeled size distributions rather than by summing the masses in the Aitken and accumulation modes has been changed such that doing so does not always improve model performance.

\section{Model sensitivities}

Four additional simulations were conducted to assess the sensitivity of modeled size distributions to changes in the aerosol model. The "BASE" model configuration used for the sensitivity runs contained various updates from CMAQ v5.0.1, but overall results of the BASE simulation used for these sensitivity studies were very similar to those presented in Sect. 3 . The three sensitivity studies included an adjustment to the apportionment of PM emissions between modes and the implementation of a gravitational settling scheme, two changes that are planned to be included in CMAQ v5.1 (scheduled for release in fall 2015). In addition, a third simulation was performed where the allowable particle mode widths (i.e., geometric standard deviations) in the model are constrained to a relatively narrow range. The details of each sensitivity analysis are described in the following three sub-sections. The sensitivity tests were each performed for May 2002 and compared to data from the three BRACE sites in Tampa during that month.

\subsection{PM emissions adjustment}

In CMAQ v5.0.2, primary anthropogenic emissions of $\mathrm{PM}_{2.5}$ $\mathrm{EC}$, organic carbon (OC), and non-carbon organic mass (NCOM; Simon and Bhave, 2012) are mostly (99.9\%) assigned to CMAQ's accumulation mode, with the remaining $0.1 \%$ assigned to the Aitken mode. Primary anthropogenic emissions of other species (i.e., sulfate, nitrate, chloride, ammonium, sodium, water, and "other") are $100 \%$ assigned to the accumulation mode. As noted by Elleman and Covert (2010), these modal mass fractions are based on historical measurements that underestimated ultrafine particles. In an effort to improve simulation of aerosol number size distributions, Elleman and Covert (2010) updated particulate emissions size distributions based on a review of modern measurements in regions dominated by urban, power plant, and marine sources at $4-15 \mathrm{~km}$ spatial scales. In the "PMEMIS" sensitivity test, the modal mass fractions for "urban" PM emissions from Elleman and Covert (2010) (i.e., 10\% Aitken mode, $90 \%$ accumulation mode) were applied to all primary anthropogenic $\mathrm{PM}_{2.5}$ emissions. In addition, the modal parameters characterizing the emitted particles (i.e., geometric mean volume diameter and standard deviation) were modified. The updated emission parameters and their base case values are listed in Table 3. Anthropogenic emissions of coarse PM, as well as sea spray and windblown dust, were unchanged.

The change in particle size distribution for $\mathrm{SO}_{4}^{2-}$ and $\mathrm{Na}^{+}$ at the three BRACE sites when implementing the PM emissions adjustment is shown in Fig. 10. Particle size distributions are narrower and shifted toward smaller sizes in the PMEMIS simulation compared to the BASE simulation, in better agreement with the observations. This model change affects only the fine-mode peak (e.g., $\mathrm{SO}_{4}^{2-}$ ) and does not impact the coarse-mode peak (e.g., $\mathrm{Na}^{+}$). Overall, changing the input PM emissions distribution improves CMAQ estimated inorganic particle size distributions compared to the observations.

\subsection{Constrained mode widths}

CMAQ uses three lognormal modes to model the aerosol size distribution, where each mode is characterized by three parameters: particle number, geometric mean diameter, and geometric standard deviation (Binkowski and Roselle, 2003). Though the mode standard deviations (widths) are calculated as prognostic variables within the aerosol code, they are constrained between the values 1.05 and 2.50. Furthermore, due 
Table 3. Parameters for Aitken and accumulation-mode particulate emissions for the BASE run and PMEMIS sensitivity case.

\begin{tabular}{|c|c|c|c|c|c|c|c|}
\hline \multirow[b]{2}{*}{ Mode } & \multirow[b]{2}{*}{ Species } & \multicolumn{3}{|c|}{ BASE } & \multicolumn{3}{|c|}{ PMEMIS } \\
\hline & & $\begin{array}{l}\text { Mass } \\
\text { fraction }\end{array}$ & $D_{\mathrm{gv}}(\mu \mathrm{m})$ & $\sigma_{\mathrm{g}}$ & $\begin{array}{l}\text { Mass } \\
\text { fraction }\end{array}$ & $D_{\mathrm{gv}}(\mu \mathrm{m})$ & $\sigma_{\mathrm{g}}$ \\
\hline \multirow[t]{2}{*}{ Aitken } & EC/OC/NCOM & 0.001 & 0.030 & 1.7 & 0.10 & 0.060 & 1.7 \\
\hline & Other & 0.000 & 0.030 & 1.7 & 0.10 & 0.060 & 1.7 \\
\hline \multirow{2}{*}{ Accumulation } & EC/OC/NCOM & 0.999 & 0.300 & 2.0 & 0.90 & 0.280 & 1.7 \\
\hline & Other & 1.000 & 0.300 & 2.0 & 0.90 & 0.280 & 1.7 \\
\hline
\end{tabular}
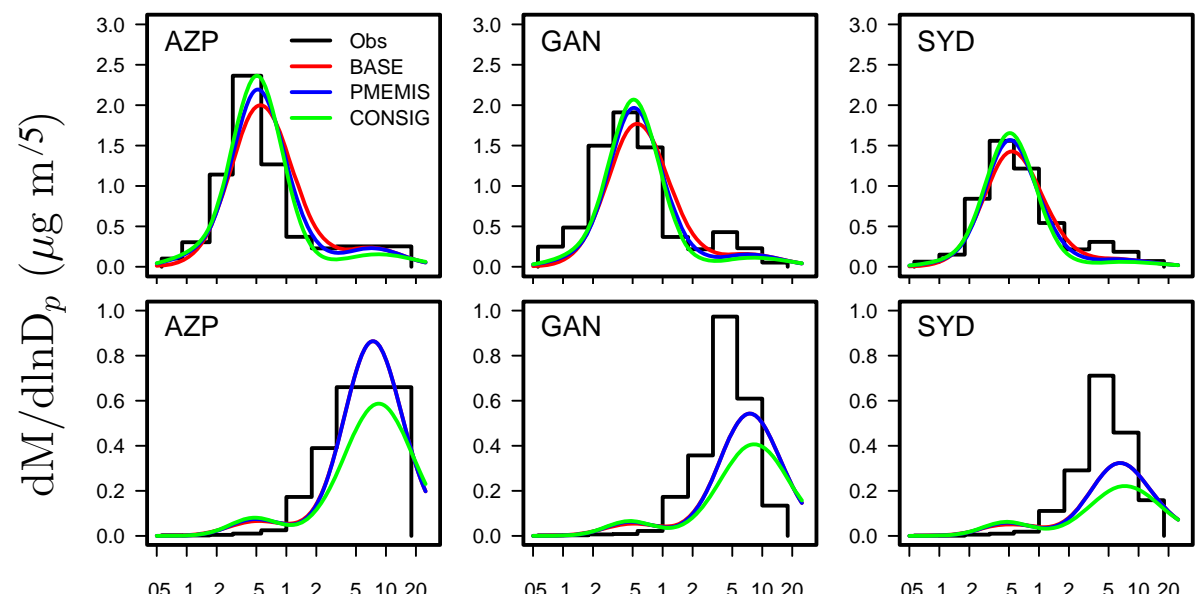

Aerodynamic diameter $(\mu \mathrm{m})$

Figure 10. Observed and modeled $\mathrm{SO}_{4}^{2-}$ (top) and $\mathrm{Na}^{+}$(bottom) size distributions for the PMEMIS and CONSIG sensitivity simulations.

to numerical instabilities the coarse-mode width is not allowed to vary during condensation and evaporation (Kelly et al., 2010). CMAQ mode widths often reach the allowed upper bound, which reduces confidence that they are being simulated accurately. Several other state-of-the-science modal aerosol models use fixed mode widths, e.g., COSMOART (Vogel et al., 2009) and MESSy/MADE3 (Kaiser et al., 2014), though other models also allow mode widths to vary (e.g., RAQM2/MADMS; Kajino et al., 2012). To explore how using fixed mode widths might affect CMAQ simulated size distributions, a model sensitivity study "CONSIG" based on the PMEMIS simulation was conducted in which the modal standard deviation constraints were modified from 1.05-2.50 to \pm 0.1 from their emitted values; i.e., the Aitkenmode and accumulation-mode standard deviations were constrained between 1.6 and 1.8, while the coarse-mode standard deviation was constrained between 2.1 and 2.3.

The difference in particle size distribution between the PMEMIS simulation and the CONSIG simulation is also shown in Fig. 10. Constraining the mode widths tends to produce an accumulation-mode peak that is narrower and shifted to smaller sizes than the PMEMIS simulation, resulting in a better comparison against the observations. For the coarse mode, however, constraining the mode widths results in a wider and lower peak than the PMEMIS simulations, which does not compare as well to the observations. Of course, the impact on model performance is directly dependent on the values chosen to constrain the particle mode widths, and alternative constraints could potentially improve performance for the coarse mode. These results do suggest, however, that the modeled size distribution is sensitive to the treatment of the mode widths, and that improvements in the algorithm that computes them would be beneficial.

\subsection{Gravitational settling}

Although the CMAQ aerosol module simulates gravitational settling for particles in the lowest model layer in computing their dry deposition velocities (Binkowski and Roselle, 2003), a potential limitation of the approach is the absence of gravitational settling for particles above layer 1. As a result, coarse particles emitted or convectively mixed above the first model layer can artificially remain aloft and be transported downwind farther than is realistic. As part of the development for CMAQ v5.1, a gravitational settling scheme has been implemented in which settling velocities are calculated for accumulation and coarse-mode aerosol zeroth, second, 


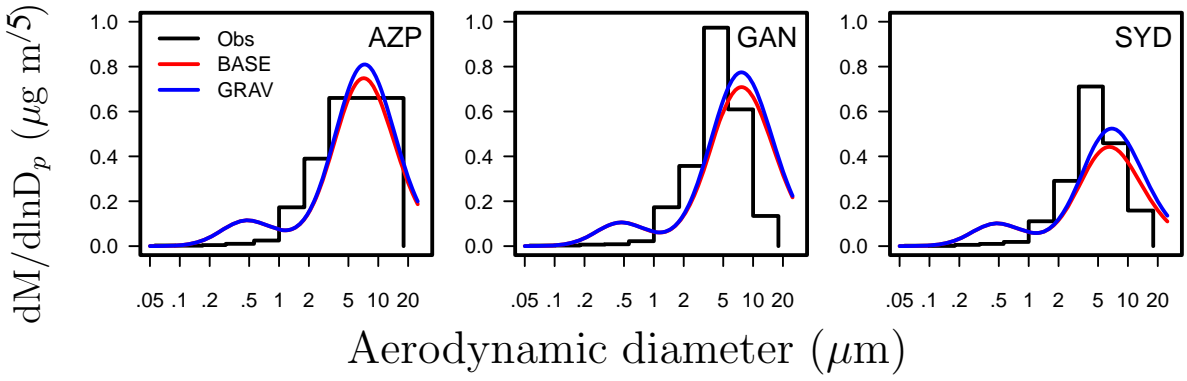

Figure 11. Observed and modeled $\mathrm{Na}^{+}$size distributions for the GRAV sensitivity simulation.

and third moments in each grid cell. The method is a Stokes law approach using the same equations used in computing aerosol deposition velocities to the surface in layer 1 (see Eqs. A31-A32 in Binkowski and Shankar, 1995). The settling velocities are then used in a sedimentation sub-module to calculate the moment fluxes through model layers using a first-order upstream relation.

The difference in average $\mathrm{Na}^{+}$size distributions simulated with and without gravitational settling is shown in Fig. 11. Because the impact of gravitational settling is significant only for larger particles, there is no discernible effect on the fine-mode range of the aerosol size distribution when gravitational settling is included. However, there is a substantial increase in the coarse-mode size range. The coarse-mode peak is higher at the coastal BRACE sites in the GRAV simulation due to particles settling from upper model layers into the lowest model layer, increasing the overall surface layer concentration. The impact of gravitational settling is much less significant for inland locations that are not as impacted by sea spray. Including the effects of gravitational settling has only a very minor impact on modeled $\mathrm{PM}_{2.5}$ mass.

\section{Summary and conclusions}

Size-resolved particle ion $\mathrm{SO}_{4}^{2-}, \mathrm{NO}_{3}^{-}, \mathrm{NH}_{4}^{+}, \mathrm{Cl}^{-}, \mathrm{Na}^{+}$, $\mathrm{Mg}^{2+}, \mathrm{Ca}^{2+}$, and $\mathrm{K}^{+}$measurements for sites located throughout the USA and Canada in 2002-2005 were compared to CMAQ v5.0.1 model output to assess the ability of the model to reproduce the observed particle mass size distribution. A total of 24 different measurement campaigns (some sites measured in two different seasons) were available across the 4 years. The model was generally able to reproduce the observed $\mathrm{SO}_{4}^{2-}$ and $\mathrm{NH}_{4}^{+}$distributions at most of the sites, but tended to overestimate the peak diameter and underestimate the peak particle concentration. $\mathrm{NH}_{4}^{+}$was substantially underestimated at the SGO site, likely due to underestimated $\mathrm{NH}_{3}$ emissions in California's South Coast Air Basin.

CMAQ was generally able to capture the size distribution and higher concentrations of $\mathrm{Na}^{+}$and $\mathrm{Cl}^{-}$at coastal and near-coastal sites. The model also reasonably captures $\mathrm{Mg}^{2+}$ concentrations and size distributions for those sites where $\mathrm{Mg}^{2+}$ originates from sea spray (e.g., the three BRACE sites in Florida), but underpredicts at sites influenced by soil dust, particularly in the western portion of the modeling domain. The model substantially underpredicts $\mathrm{Ca}^{2+}$ at many coastal sites. At some inland sites, however, model performance for $\mathrm{Ca}^{2+}$ is better than the model performance for $\mathrm{Mg}^{2+}$. The difference in performance may be attributable to errors in windblown dust emissions as well as speciation profiles for windblown and anthropogenic fugitive dust. $\mathrm{K}^{+}$, which has contributions from residential wood combustion and wildfires as well as sea spray, exhibits somewhat better model performance than $\mathrm{Ca}^{2+}$. Model performance for $\mathrm{NO}_{3}^{-}$was mixed, with good performance at some sites (e.g., BRL, CHA1, KEJ1, and LED2), overpredicted concentrations in the accumulation-mode size range at some sites (e.g., BRG, FRS, and SPR2), and substantially underestimated accumulation mode $\mathrm{NO}_{3}^{-}$at $\mathrm{SGO} 1$ and underestimated coarse particle concentrations at other sites (e.g., GRC, GSM, and YOS).

An examination of the difference in model performance between calculating $\mathrm{PM}_{2.5}$ mass from the modeled size distribution or by summing the masses in the Aitken and accumulation modes $\left(\mathrm{PM}_{i j}\right)$ shows that using the size distribution parameters results in values that on average are smaller by $0.3-1.2 \mu \mathrm{g} \mathrm{m}^{-3}$. On a daily basis, the difference between $\mathrm{PM}_{2.5}$ and $\mathrm{PM}_{i j}$ is usually less than $1 \mu \mathrm{g} \mathrm{m}^{-3}$, regardless of season or year. The largest differences between $\mathrm{PM}_{2.5}$ and $\mathrm{PM}_{i j}$ occur in the eastern USA during the summer. Concentrations of $\mathrm{SO}_{4}^{2-}$ are much higher in the eastern USA than in the west. Higher humidities in the eastern USA, together with the high hygroscopicity of $\mathrm{SO}_{4}^{2-}$, lead to growth of the accumulation mode beyond the $2.5 \mu \mathrm{m}$ size range.

For operational model evaluation, the difference in aggregated model performance between the two methods in comparison to observations is generally very small. Regionalscale assessments based on determination of relative response factors (RRFs), such as development of state implementation plans, would likely be unaffected by the choice of using $\mathrm{PM}_{2.5}$ or $\mathrm{PM}_{i j}$. For studies that involve absolute contributions of PM, particularly at the fine scale, the difference between $\mathrm{PM}_{2.5}$ and $\mathrm{PM}_{i j}$ may warrant further consideration. The data set used here, consisting of observations at mostly 
rural locations and limited to inorganic components of PM, as well as modeling conducted using relatively coarse $36 \mathrm{~km}$ grid cells, does not allow us to conclude which approach is more accurate in all cases. In urban areas dominated by primary emissions, $\mathrm{PM}_{i j}$ may be preferable to ensure consistency with emission inventories, as the $\mathrm{PM}_{2.5}$ approach would immediately apportion some fraction of primary emissions to being outside the $2.5 \mu \mathrm{m}$ size range. In remote or western regions, however, where PM is highly aged or dust is a main contributor, $\mathrm{PM}_{2.5}$ may be preferable to account for growth outside the $2.5 \mu \mathrm{m}$ size range or the sub- $2.5 \mu \mathrm{m}$ shoulder of the coarse mode.

Two updates to the aerosol model that are scheduled for the next release of CMAQ were evaluated. Increasing the fraction of primary PM emissions apportioned to the Aitken mode from 0.1 to $10 \%$ and modifying the geometric mean diameter and standard deviation of the emitted particles, as recommended by Elleman and Covert (2010), caused the peak diameter of the accumulation mode to decrease, in better agreement with the observations. Implementing gravitational settling for the accumulation and coarse modes for layers above the lowest model layer led to an increase in coarse mode $\mathrm{Na}^{+}$from sea spray near the coast. Finally, an experiment in which the mode standard deviations were constrained to a relatively narrow range led to further reduction of accumulation-mode peak diameters. Given the sensitivity of the size distribution to the treatment of mode standard deviations, future work should focus on determining the best approach for representing these variables in the model.

It is important to note that this evaluation of the CMAQ modeled aerosol size distributions has focused on the mass size distribution and has considered only inorganic species. As understanding of the health impacts associated with particular PM components and size ranges develops (e.g., Delfino et al., 2011), evaluating predictions of carbonaceous and ultrafine particle size distributions in urban environments could be valuable to support health and exposure applications. Similarly, as the state of the science evolves toward more frequent use of the two-way coupled WRF-CMAQ model (Wong et al., 2012) to capture the influence of air pollution on atmospheric dynamics, particularly the effect on clouds (Yu et al., 2014), it will be important to evaluate modeled aerosol number and surface area distributions as well.

\section{Code availability}

CMAQ model documentation and released versions of the source code are available at www.cmaq-model.org. The updates described here, as well as model postprocessing scripts, are available upon request.

\section{The Supplement related to this article is available online} at doi:10.5194/gmd-8-2877-2015-supplement.
Acknowledgements. We thank Taehyoung Lee (Colorado State University), Noreen Poor (University of South Florida), and Charles Stanier (University of Iowa) for providing MOUDI measurements that helped make this analysis possible. Brett Gantt and Rohit Mathur (US EPA) provided constructive comments in reviewing this manuscript. We thank Heather Simon and George Pouliot (US EPA) for their assistance with PM profiles in the SPECIATE database. The United States Environmental Protection Agency through its Office of Research and Development supported the research described here. It has been subjected to Agency review and approved for publication. The views and interpretations in this publication are those of the authors and are not necessarily attributable to their organizations.

Edited by: G. A. Folberth

\section{References}

Allen, D. J., Pickering, K. E., Pinder, R. W., Henderson, B. H., Appel, K. W., and Prados, A.: Impact of lightning-NO on eastern United States photochemistry during the summer of 2006 as determined using the CMAQ model, Atmos. Chem. Phys., 12, 1737-1758, doi:10.5194/acp-12-1737-2012, 2012.

Appel, K. W., Bhave, P. V., Gilliland, A. B., Sarwar, G., and Roselle, S. J.: Evaluation of the Community Multiscale Air Quality (CMAQ) model version 4.5: sensitivities impacting model performance; Part II - Particulate matter, Atmos. Environ., 42, 6057-6066, doi:10.1016/j.atmosenv.2008.03.036, 2008.

Appel, K. W., Pouliot, G. A., Simon, H., Sarwar, G., Pye, H. O. T., Napelenok, S. L., Akhtar, F., and Roselle, S. J.: Evaluation of dust and trace metal estimates from the Community Multiscale Air Quality (CMAQ) model version 5.0, Geosci. Model Dev., 6, 883-899, doi:10.5194/gmd-6-883-2013, 2013.

Asgharian, B., Hofmann, W., and Bergmann, R.: Particle deposition in a multiple-path model of the human lung, Aerosol Sci. Technol., 34, 332-339, 2001.

Baker, K. R. and Foley, K. M.: A nonlinear regression model estimating single source concentrations of primary and secondarily formed $\mathrm{PM}_{2.5}$, Atmos. Environ., 45, 3758-3767, doi:10.1016/j.atmosenv.2011.03.074, 2011.

Bash, J. O., Cooter, E. J., Dennis, R. L., Walker, J. T., and Pleim, J. E.: Evaluation of a regional air-quality model with bidirectional NH3 exchange coupled to an agroecosystem model, Biogeosciences, 10, 1635-1645, doi:10.5194/bg-10-1635-2013, 2013.

Bey, I., Jacob, D. J., Yantosca, R. M., Logan, J. A., Field, B. D., Fiore, A. M., Li, Q., Liu, H. Y., Mickley, L. J., and Schulz, M. G.: Global modeling of tropospheric chemistry with assimilated meteorology: model description and evaluation, J. Geophys. Res., 106, 23073-23095, doi:10.1029/2001JD000807, 2001.

Binkowski, F. S. and Roselle, S. J.: Models-3 Community Multiscale Air Quality (CMAQ) model aerosol component. 1. Model description, J. Geophys. Res., 108, 4183-4201, 2003.

Binkowski, F. S. and Shankar, U.: The Regional Particulate Matter Model 1. Model description and preliminary results, J. Geophys. Res., 100, 26191-26209, 1995.

Cabada, J. C., Rees, S., Takahama, S., Khlystov, A., Pandis, S. N., Davidson, C. I., and Robinson, A. L.: Mass size distributions and size resolved chemical composition of fine particulate mat- 
ter at the Pittsburgh supersite, Atmos. Environ., 38, 3127-3141, doi:10.1016/j.atmosenv.2004.03.004, 2004.

Carlton, A. G., Bhave, P. V., Napelenok, S. L., Edney, E. O., Sarwar, G., Pinder, R. W., Pouliot, G. A., and Houyoux, M.: Model representation of secondary organic aerosol in CMAQv4.7, Environ. Sci. Technol., 44, 8553-8560, doi:10.1021/es100636q, 2010.

Cooter, E. J., Bash, J. O., Benson, V., and Ran, L.: Linking agricultural crop management and air quality models for regional to national-scale nitrogen assessments, Biogeosciences, 9, 40234035, doi:10.5194/bg-9-4023-2012, 2012.

Delfino, R. J., Staimer, N., and Vaziri, N. D.: Air pollution and circulating biomarkers of oxidative stress, Air Qual. Atmos. Health, 4, 37-52, doi:10.1007/s11869-010-0095-2, 2011.

Elleman, R. A. and Covert, D. S.: Aerosol size distribution modeling with the Community Multiscale Air Quality modeling system in the Pacific northwest: 3. Size distribution of particles emitted into a mesoscale model, J. Geophys. Res., 115, D03204, doi:10.1029/2009JD012401, 2010.

Evans, M. C., Campbell, S. W., Bhethanabotla, V., and Poor, N. D.: Effect of sea salt and calcium carbonate interactions with nitric acid on the direct dry deposition of nitrogen to Tampa Bay, Florida, Atmos. Environ., 38, 4847-4858, 2004.

Foley, K. M., Roselle, S. J., Appel, K. W., Bhave, P. V., Pleim, J. E., Otte, T. L., Mathur, R., Sarwar, G., Young, J. O., Gilliam, R. C., Nolte, C. G., Kelly, J. T., Gilliland, A. B., and Bash, J. O.: Incremental testing of the Community Multiscale Air Quality (CMAQ) modeling system version 4.7, Geosci. Model Dev., 3, 205-226, doi:10.5194/gmd-3-205-2010, 2010.

Fountoukis, C. and Nenes, A.: ISORROPIA II: a computationally efficient thermodynamic equilibrium model for $\mathrm{K}^{+}$ $\mathrm{Ca}^{2+}-\mathrm{Mg}^{2+}-\mathrm{NH}_{4}^{+}-\mathrm{Na}^{+}-\mathrm{SO}_{4}^{2-}-\mathrm{NO}_{3}^{-}-\mathrm{Cl}^{-}-\mathrm{H}_{2} \mathrm{O}$ aerosols, Atmos. Chem. Phys., 7, 4639-4659, doi:10.5194/acp-7-4639-2007, 2007.

Frank, N. H.: Retained Nitrate, Hydrated Sulfates, and Carbonaceous Mass in Federal Reference Method Fine Particulate Matter for Six Eastern U.S. Cities, J. Air Waste Manage. Assoc., 56, 500-511, 2006.

Henderson, B. H., Akhtar, F., Pye, H. O. T., Napelenok, S. L., and Hutzell, W. T.: A database and tool for boundary conditions for regional air quality modeling: description and evaluation, Geosci. Model Dev., 7, 339-360, doi:10.5194/gmd-7-3392014, 2014.

Herner, J. D., Aw, J., Gao, O., Chang, D. P., and Kleeman, M. J.: Size and composition distribution of airborne particulate mattern in northern California: I - Particulate mass, carbon, and water-soluble ions, J. Air Waste Manage., 55, 30-51, doi:10.1080/10473289.2005.10464600, 2005.

Houyoux, M. R., Vukovich, J. M., Coats Jr., C. J., Wheeler, N. J. M., and Kasibhatla, P. S.: Emission inventory development and processing for the Seasonal Model for Regional Air Quality (SMRAQ) project, J. Geophys. Res., 105, 9079-9090, 2000.

Jiang, W., Smyth, S., Giroux, É., Roth, H., and Yin, D.: Differences between CMAQ fine mode particle and $\mathrm{PM}_{2.5}$ concentrations and their impact on model performance evaluation in the lower Fraser Valley, Atmos. Environ., 40, 4973-4985, doi:10.1016/j.atmosenv.2005.10.069, 2006.

Kain, J. S.: The Kain-Fritsch convective parameterization: an update, J. Appl. Meteorol., 43, 170-181, doi:10.1175/15200450(2004)043<0170:TKCPAU>2.0.CO;2, 2004.
Kaiser, J. C., Hendricks, J., Righi, M., Riemer, N., Zaveri, R. A., Metzger, S., and Aquila, V.: The MESSy aerosol submodel MADE3 (v2.0b): description and a box model test, Geosci. Model Dev., 7, 1137-1157, doi:10.5194/gmd-7-11372014, 2014.

Kajino, M., Inomata, Y., Sato, K., Ueda, H., Han, Z., An, J., Katata, G., Deushi, M., Maki, T., Oshima, N., Kurokawa, J., Ohara, T., Takami, A., and Hatakeyama, S.: Development of the RAQM2 aerosol chemical transport model and predictions of the Northeast Asian aerosol mass, size, chemistry, and mixing type, Atmos. Chem. Phys., 12, 11833-11856, doi:10.5194/acp12-11833-2012, 2012.

Kelly, J. T., Bhave, P. V., Nolte, C. G., Shankar, U., and Foley, K. M.: Simulating emission and chemical evolution of coarse seasalt particles in the Community Multiscale Air Quality (CMAQ) model, Geosci. Model Dev., 3, 257-273, doi:10.5194/gmd-3257-2010, 2010.

Kelly, J. T., Avise, J., Cai, C., and Kaduwela, A. P.: Simulating particle size distributions over California and impact on lung deposition fraction, Aerosol Sci. Technol., 45, 148-162, doi:10.1080/02786826.2010.528078, 2011.

Kelly, J. T., Baker, K. R., Nowak, J. B., Murphy, J. G., Markovic, M. Z., VandenBoer, T. C., Ellis, R. A., Neuman, J. A., Weber, R. J., Roberts, J. M., Veres, P. R., de Gouw, J. A., Beaver, M. R., Newman, S., and Misenis, C.: Fine-scale simulation of ammonium and nitrate over the South Coast Air Basin and San Joaquin Valley of California during CalNex-2010, J. Geophys. Res., 119, 3600-3614, doi:10.1002/2013JD021290, 2014.

Lee, T.: Characterizing ionic components of aerosol in rural environments: temporal variability, size distributions, and the form of particle nitrate, PhD thesis, Colorado State University, 2007.

Lee, T., Yu, X.-Y., Ayres, B., Kreidenweis, S. M., Malm, W. C., and Collett Jr., J. L.: Observations of fine and coarse particle nitrate at several rural locations in the United States, Atmos. Environ. 42, 2720-2732, doi:10.1016/j.atmosenv.2007.05.016, 2008a.

Lee, T., Yu, X.-Y., Kreidenweis, S. M., Malm, W. C., and Collett Jr., J. L.: Semi-continuous measurement of $\mathrm{PM}_{2.5}$ ionic composition at several rural locations in the United States, Atmos. Environ., 42, 6655-6669, doi:10.1016/j.atmosenv.2008.04.023, 2008b.

Malm, W. C., Day, D. E., Carrico, C., Kreidenweis, S. M., Collett Jr., J. L., McMeeking, G., Lee, T., Carillo, J., and Schichtel, B.: Intercomparison and closure calculations using measurements of aerosol species and optical properties during the Yosemite Aerosol Characterization Study, J. Geophys. Res., 110, D14302, doi:10.1029/2004JD005494, 2005.

Marple, V. A., Rubow, K. L., and Behm, S. M.: A Microorifice Uniform Deposit Impactor (MOUDI): description, calibration, and use, Aerosol Sci. Technol., 14, 434-446, doi:10.1080/02786829108959504, 1991.

Morrison, H., Thompson, G., and Tatarskii, V.: Impact of cloud microphysics on the development of trailing stratiform precipitation in a simulated squall line: comparison of one- and two-moment schemes, Mon. Weather Rev., 137, 991-1007, doi:10.1175/2008MWR2556.1, 2009.

Nolte, C. G., Bhave, P. V., Arnold, J. R., Dennis, R. L., Zhang, K. M., and Wexler, A. S.: Modeling urban and regional aerosols-Application of the CMAQ-UCD aerosol model 
to Tampa, a coastal urban site, Atmos. Environ., 42, 3179-3191, doi:10.1016/j.atmosenv.2007.12.059, 2008.

Nowak, J. B., Neuman, J. A., Bahreini, R., Middlebrook, A. M., Holloway, J. S., McKeen, S. A., Parrish, D. D., Ryerson, T. B., and Trainer, M.: Ammonia sources in the California South Coast Air Basin and their impact on ammonium nitrate formation, Geophys. Res. Lett., 39, L07804, doi:10.1029/2012GL051197, 2012.

Otte, T. L. and Pleim, J. E.: The Meteorology-Chemistry Interface Processor (MCIP) for the CMAQ modeling system: updates through MCIPv3.4.1, Geosci. Model Dev., 3, 243-256, doi:10.5194/gmd-3-243-2010, 2010.

Pleim, J. E.: A combined local and non-local closure model for the atmospheric boundary layer. Part 1: Model description and testing, J. Appl. Meteorol. Clim., 46, 1383-1395, doi:10.1175/JAM2539.1, 2007a.

Pleim, J. E.: A combined local and non-local closure model for the atmospheric boundary layer. Part 2: Application and evaluation in a mesoscale model, J. Appl. Meteorol. Clim., 46, 1396-1409, doi:10.1175/JAM2534.1, 2007b.

Pleim, J. E. and Xiu, A.: Development and testing of a surface flux and planetary boundary model for application in mesoscale models, J. Appl. Meteorol., 34, 16-32, doi:10.1175/1520-045034.1.16, 1995.

Raffuse, S. M., Pryden, D. A., Sullivan, D. C., Larkin, N. K., Strand, T., and Solomon, R.: SMARTFIRE algorithm description, Sonoma Technol., Inc., Petaluma, Calif., available at: http://firesmoke.ca/smartfire/pdfs/SMARTFIRE_Algorithm_ Description_Final.pdf (last access: 12 May 2015), 2009.

Reff, A., Bhave, P. V., Simon, H., Pace, T. G., Pouliot, G. A., Mobley, J. D., and Houyoux, M.: Emissions inventory of $\mathrm{PM}_{2.5}$ trace elements across the United States, Environ. Sci. Technol., 43, 5790-5796, doi:10.1021/es802930x, 2009.

Sarwar, G., Appel, K. W., Carlton, A. G., Mathur, R., Schere, K., Zhang, R., and Majeed, M. A.: Impact of a new condensed toluene mechanism on air quality model predictions in the US, Geosci. Model Dev., 4, 183-193, doi:10.5194/gmd-4-183-2011, 2011.

Scheffe, R. D., Lynch, J. A., Reff, A., Kelly, J. T., Hubbell, B., Greaver, T. L., and Smith, J. T.: The Aquatic Acidification Index: a new regulatory metric linking atmospheric and biogeochemical models to assess potential aquatic ecosystem recovery, Water Air Soil Poll., 225, 1838, doi:10.1007/s11270-013-1838-0, 2014.

Simon, H. and Bhave, P. V.: Simulating the Degree of Oxidation in Atmospheric Organic Particles, Environ. Sci. Technol., 46, 331339, doi:10.1021/es202361w, 2012.

Simon, H., Beck, L., Bhave, P. V., Divita, F., Hsu, Y., Luecken, D., Mobley, J. D., Pouliot, G. A., Reff, A., Sarwar, G., and Strum, M.: The development and uses of EPA's SPECIATE database, Atmos. Poll. Res., 1, 196-206, doi:10.5094/APR.2010.026, 2010.
Simon, H., Baker, K. R., and Phillips, S.: Compilation and interpretation of photochemical model performance statistics published between 2006 and 2012, Atmos. Environ., 61, 124-139, doi:10.1016/j.atmosenv.2012.07.012, 2012.

Skamarock, W. C. and Klemp, J. B.: A time-split nonhydrostatic atmospheric model for weather research and forecasting applications, J. Comput. Phys., 227, 3465-3485, doi:10.1016/j.jcp.2007.01.037, 2008.

Stanier, C. O., Khlystov, A. Y., and Pandis, S. N.: Ambient aerosol size distributions and number concentrations measured during the Pittsburgh Air Quality Study (PAQS), Atmos. Environ., 38, 3275-3284, doi:10.1016/j.atmosenv.2004.03.020, 2004.

Vogel, B., Vogel, H., Bäumer, D., Bangert, M., Lundgren, K., Rinke, R., and Stanelle, T.: The comprehensive model system COSMOART - Radiative impact of aerosol on the state of the atmosphere on the regional scale, Atmos. Chem. Phys., 9, 8661-8680, doi:10.5194/acp-9-8661-2009, 2009.

Vukovich, J. M. and Pierce, T.: The implementation of BEIS3 within the SMOKE modeling framework, in: Proceedings of the 11th International Emissions Inventory Conference, Atlanta, Georgia, available at: http://www.epa.gov/ttn/chief/conference/ ei11/modeling/vukovich.pdf (last access: 11 May 2015), 2002.

Wong, D. C., Pleim, J., Mathur, R., Binkowski, F., Otte, T., Gilliam, R., Pouliot, G., Xiu, A., Young, J. O., and Kang, D.: WRFCMAQ two-way coupled system with aerosol feedback: software development and preliminary results, Geosci. Model Dev., 5, 299-312, doi:10.5194/gmd-5-299-2012, 2012.

Yao, X. and Zhang, L.: Chemical processes in sea-salt chloride depletion observed at a Canadian rural coastal site, Atmos. Environ., 46, 189-194, doi:10.1016/j.atmosenv.2011.09.081, 2012.

Yu, S., Dennis, R., Roselle, S., Nenes, A., Walker, J., Eder, B., Schere, K., Swall, J., and Roberge, W.: An assessment of the ability of three-dimensional air quality models with current thermodynamic equilibrium models to predict aerosol $\mathrm{NO}_{3}$, J. Geophys. Res., 110, D07S13, doi:10.1029/2004JD004718, 2005.

Yu, S., Mathur, R., Pleim, J., Wong, D., Gilliam, R., Alapaty, K., Zhao, C., and Liu, X.: Aerosol indirect effect on the grid-scale clouds in the two-way coupled WRF-CMAQ: model description, development, evaluation and regional analysis, Atmos. Chem. Phys., 14, 11247-11285, doi:10.5194/acp-14-11247-2014, 2014.

Zhang, L., Vet, R., Wiebe, A., Mihele, C., Sukloff, B., Chan, E., Moran, M. D., and Iqbal, S.: Characterization of the sizesegregated water-soluble inorganic ions at eight Canadian rural sites, Atmos. Chem. Phys., 8, 7133-7151, doi:10.5194/acp-87133-2008, 2008.

Zhang, Y., Liu, P., Pun, B., and Seigneur, C.: A comprehensive performance evaluation of MM5-CMAQ for the Summer 1999 Southern Oxidants Study episode - Part III: Diagnostic and mechanistic evaluations, Atmos. Environ., 40, 4856-4873, 2006. 